\title{
Soft Tissue Reconstruction of the Maxillofacial Region
}

\author{
Benjamin Turner, John Collin, and Rui Fernandes
}

\subsection{General Considerations}

The general precept of reconstructive surgery is to assess what tissue and structures are missing and what is available to replace them, ensuring that where possible 'like should replace like'. Hard tissue defects are best restored with hard tissue and soft, soft tissue. Usually skin closest to the defect will give the best cosmetic match. Hard tissue reconstruction falls outwith the remit of this chapter, but where required it should be performed first to provide the foundation for successful soft tissue reconstruction. Next, muscle and fasciocutaneous tissue should be resuspended from the maxillofacial skeleton to restore muscle function and prevent ptosis of the soft tissues. The aerodigestive tract needs to be isolated from the cranial cavity, deep neck spaces and external skin to reduce the risk of spreading infection, fistula and sinus formation. Finally, the aphorism that form follows function is germane and careful reconstruction of normal anatomy will often meet the dual goals of cosmesis and restoration of function. Anatomical subunits should be respected, and generally if the defect is greater than $50 \%$ of a subunit, better results are obtained with removal and reconstruction of the entire subunit such that scars are camouflaged within their boundary lines (Table 86.1).

For any particular defect, the choice of reconstruction can range from simple to complex, along a continuum commonly described as the 'reconstructive ladder'(Table 86.2) [1]. The

B. Turner · J. Collin

Head and Neck Oncologic and Microvascular Reconstructive Surgery, Fellowship, Jacksonville, Florida, USA

e-mail: Benjamin.Turner@jax.ufl.edu; John.Collin@jax.ufl.edu

R. Fernandes $(\varangle)$

Professor, Department of Oral and Maxillofacial Surgery,

University of Florida, Florida, USA

Division of Head and Neck Surgery, Jacksonville, Florida, USA e-mail: Rui.Fernandes@jax.ufl.edu
Table 86.1 Key concepts of reconstructive surgery

Replace like with like

Hard tissue reconstruction first

Respect anatomical units/subunits

Local skin usually best cosmetic option

Consider options within reconstructive ladder/matrix

'reconstructive matrix' has also been described as a development of this linear concept to take into account technical requirements and potential risks to the patient on additional axes (Fig. 86.1) [2].

\subsubsection{Healing by Secondary Intention}

Where there has been soft tissue loss and/or the skin is not re-approximated, healing occurs via secondary intention with deposition of granulation tissue (Fig. 86.2). Typically this results in a broader area of scar tissue and is therefore inadvisable at most sites in the maxillofacial region. Superficial defects of concave subsites (e.g. medial canthus, conchal bowl) or mucosa are the exception and may be left to heal by secondary intention with good cosmetic results.

\subsubsection{Primary Closure}

Primary closure describes the apposition of skin edges to permit healing without granulation tissue formation and minimal scaring (Fig. 86.2). Ideally lines of primary closure should coincide with the boundaries of the anatomical subunits (Fig. 86.3), such that the scar is hidden in a natural skin crease or hairline or mimics the natural highlight of the white roll of the lip, for example. Similarly, for ablative procedures involving $50 \%$ or more of an anatomical subunit, it is preferred to remove the entire subunit for these reasons. Obviously reconstruction would then entail some kind of tissue transfer. A further consideration is orientation of closure 
Table 86.2 Reconstructive ladder

$$
\begin{array}{lll}
\multicolumn{2}{l}{\text { Transplantation }} & \\
\text { Flaps } & \text { Free } & \text { Distant } \\
& \text { Pedicled } & \text { Regional } \\
& \text { Axial } & \text { Random Pattern } \\
& \text { Local } & +/ \text { - Tissue expansion } \\
\text { Grafts } \quad \text { Full Thickness } & \\
& \text { Split Thickness } & \\
\text { Primary closure } & +/ \text { - plasties } \\
\text { Secondary Intention } & +/ \text { - negative pressure dressings }
\end{array}
$$

\section{Biomaterials}

Decellularised material-Nerve/Bone/Cartilage

Dermal matrices

Synthetic materials-Hyaluronic acid/Silicone/PTFE

Growth Factors

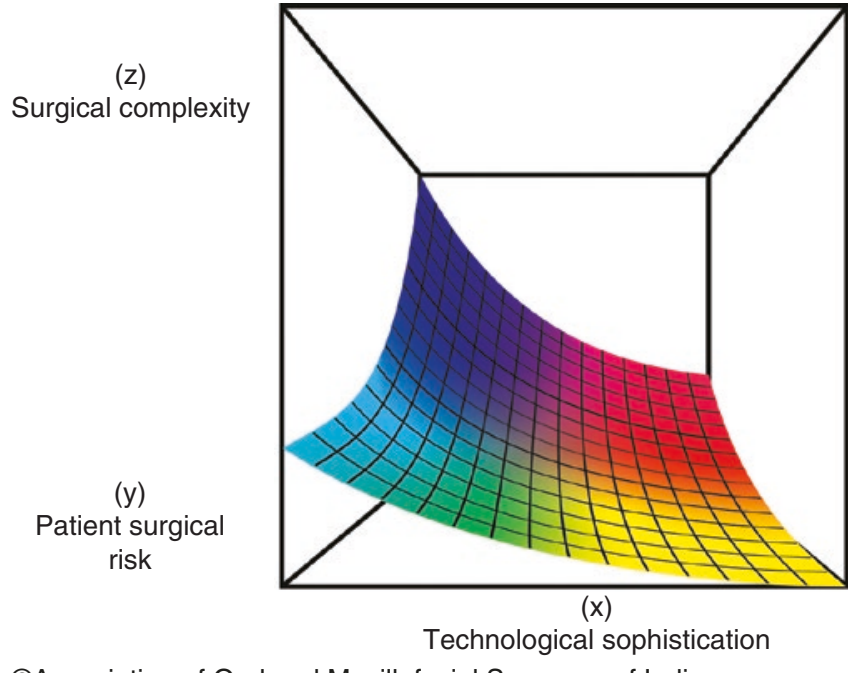

CAssociation of Oral and Maxillofacial Surgeons of India

Fig. 86.1 The reconstructive matrix

with respect to the lines of relaxed skin tension that typically run perpendicular to underlying muscle fibres where possible. These two factors may dictate the decision to excise further tissue in a traumatic injury. The temptation to excise and close primarily out with these orientations should be avoided; however, as unless tissue is grossly contaminated or frankly necrotic, a straight surgical scar is usually more prominent than random pattern scars. The generous vascular supply of the face means that it is always best to err on the side of caution and perform minimal debridement such that a maximum of soft tissue is preserved.
Primary closure is appropriate for small defects that can be closed without significant tension or distortion of key areas such as the apertures of the mouth, nares and orbit. The latter is particularly sensitive to these effects and can result in ectropion and ocular sequelae if appropriate care is not taken. Techniques such as a creating a superior lateral canthal curve to the Mustarde flap, canthopexy and Frost sutures can be employed to reduce the risk of ectropion.

\subsubsection{Grafts}

The third rung of the reconstructive ladder is occupied by grafts, which may be further categorized as simple if composed of a single tissue type-commonly split or full-thickness skin but also mucosal grafts, or composite when containing more than one tissue type. Generally they are autografts, although xenografts and bioengineered material such as porcine collagen (Permacol), Polytetrafluoroethylene, fish skin and dermal matrix (e.g. Integra) have certain utility in maxillofacial reconstruction (Table 86.2).

\subsubsection{Flaps}

Flaps may be local, pedicled (regional or distant) or free. Local flaps transfer tissue to a defect by advancement and/or rotation and are typically supplied by a random vascular pattern. Axial flaps based on a named vessel can potentially pro- 

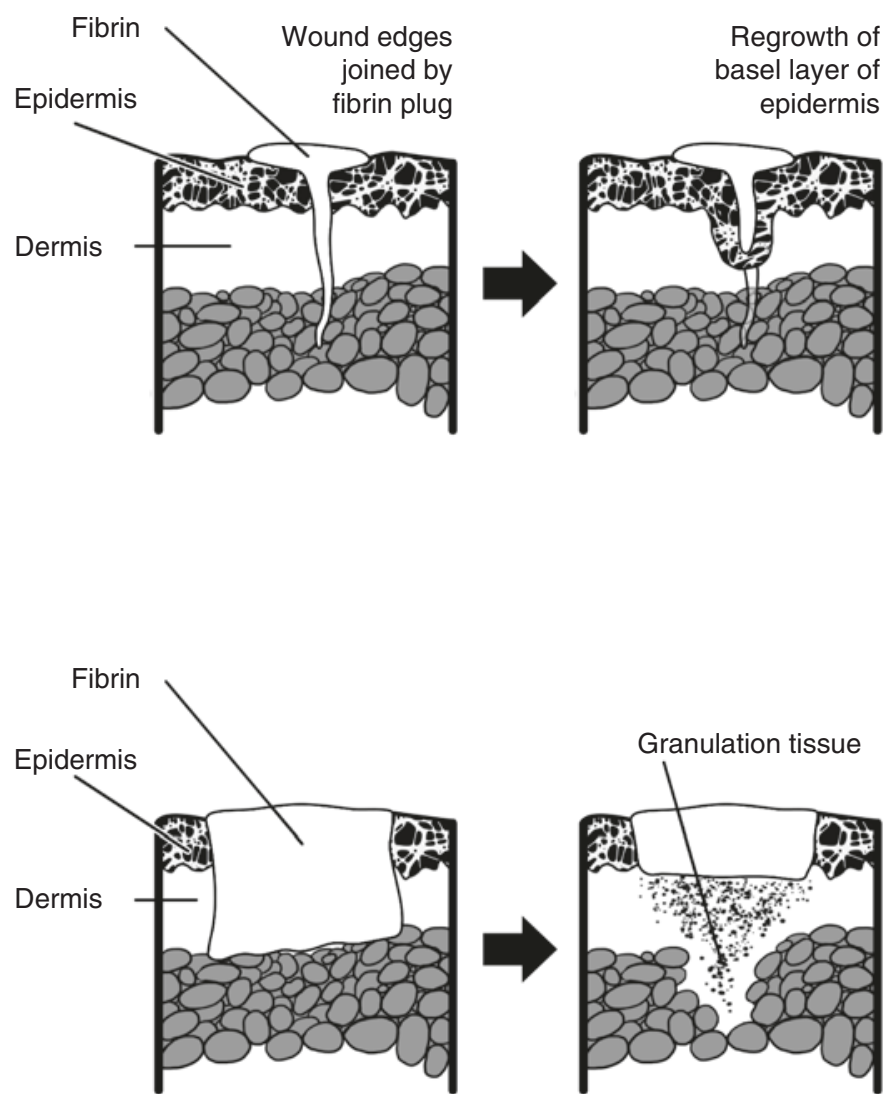

Large defect filled by fibrin cloth

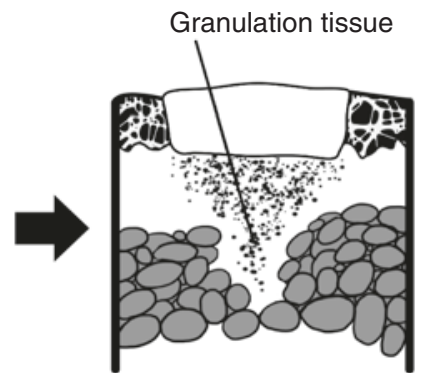

New blood vessels and fibroblasts

(granulation tissue) grown from the demis into fibrin
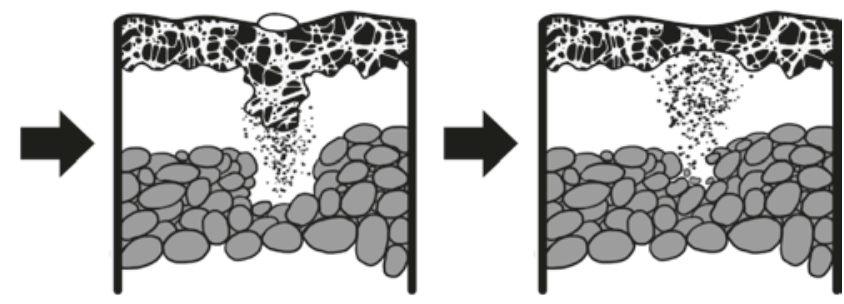

Healing by secondary intention

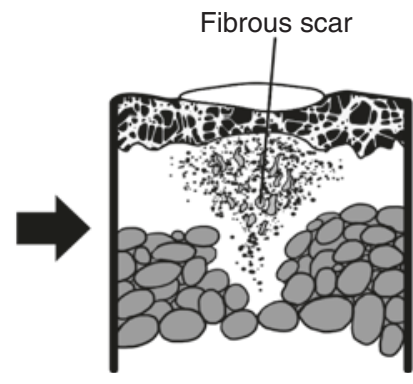

Collagen laid down by granulation tissue fibroblasts to restore integrety

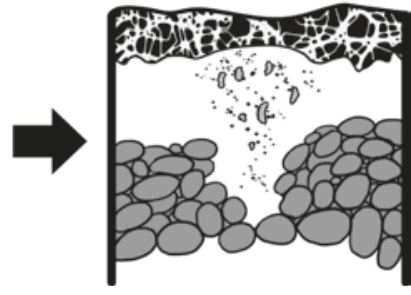

Maturation of collagen achieves structural integrity and allows regrowth of epidermis

CAssociation of Oral and Maxillofacial Surgeons of India

Fig. 86.2 Wound healing by primary and secondary intention

vide a flap of longer length to width ratio. Examples in the head and neck region include the paramedian forehead flap, nasolabial flap and facial artery myomucosal flap.

Regional pedicled flaps are able to provide a far greater area of soft tissue coverage than is possible with local flaps in the maxillofacial region, without requiring the facilities and expertise for microvascular reconstruction. They are generally less technique sensitive and susceptible to failure than microvascular free flaps; however, partial failure can still be problematic. For example, the pectoralis major myocutaneous flap has been reported to have a partial necrosis rate of up to $29 \%$ [3, 4]. Furthermore, while pedicled flaps are versatile and can usually provide a good skin match, free tissue transfer can often be a better option.

Free flaps offer many reconstructive options and can provide good cosmetic and functional outcomes. They may be sub-classified according to the tissue they contain and whether the pedicle is a named vessel or from a perforator system. Free flaps are available to reconstruct practically any size of defect in the maxillofacial region. Freedom from a pedicle allows them to be placed in any location, native vessels permitting. 
Fig. 86.3 Facial aesthetic units (Also refer Fig. 49.2)

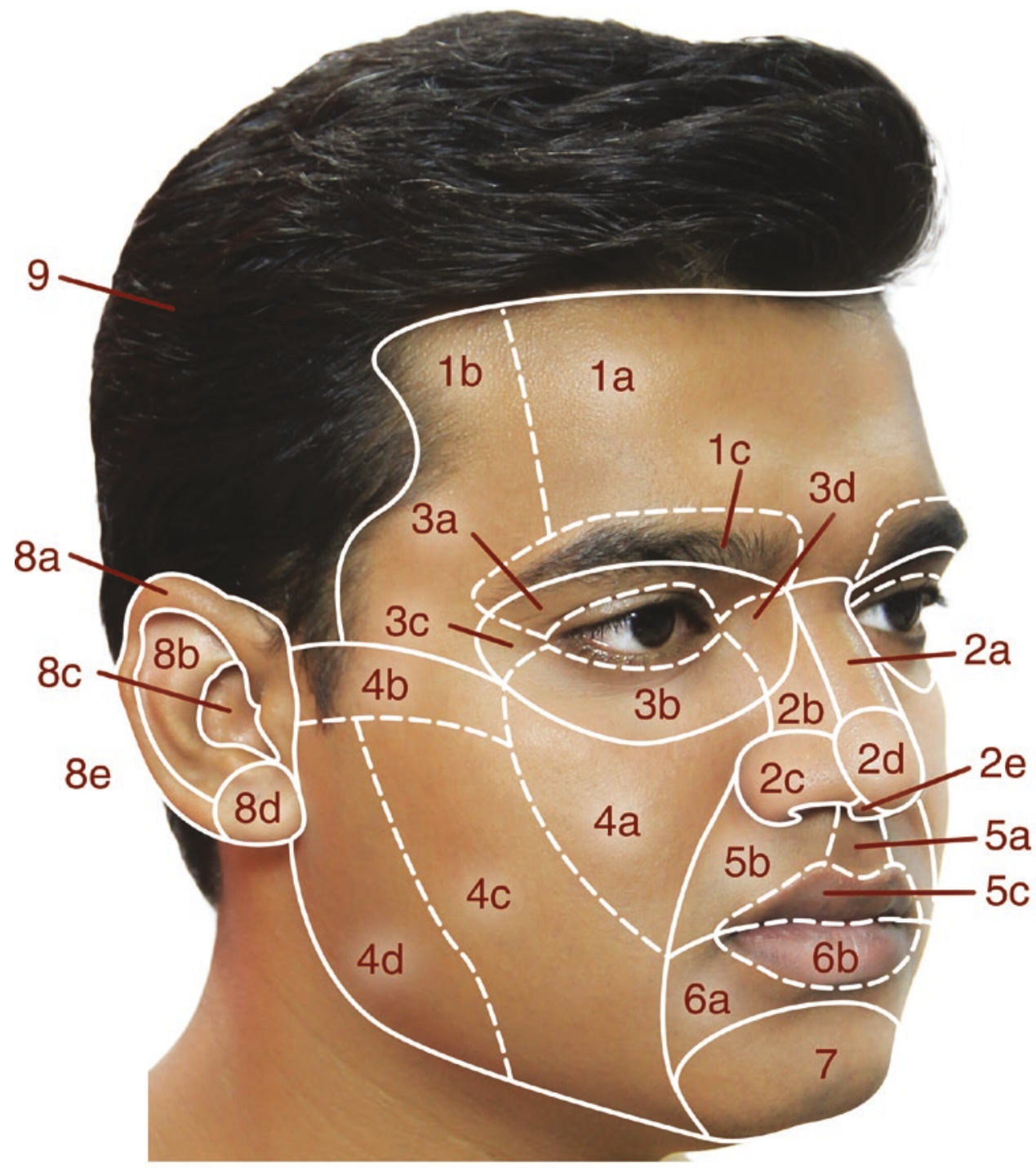

Facial Cosmetic Units

\section{Forehead: \\ 1a. Central \\ 1b. Lateral \\ 1c. Brow \\ 2. Nose: \\ 2a. Dorsum \\ $2 b$. Lateral wall \\ 2c. Ala \\ 2d. Tip \\ 2e. Columella}

3. Eyelid:

3a. Superior

3b. Inferior

3c. Lateral canthus

3d. Medial canthus
4. Cheek:
4a. Infraorbital
4b. Zygomatic

4. Cheek:

4a. Infraorbital

4b. Zygomatic

4c. Buccal

4d. Parotid-masseteric

5. Upper lip:

5a. Philtrum

5b. Lateral

5c. Vermilion

6. Lower lip:

6b. Vermilion

7. Chin 6a. Central
8. Ear:

8a. Helix

8b. Antihelix

8c. Concha

$8 \mathrm{~d}$. Earlobe

8e. Retroauricular

9. Scalp
(CAssociation of Oral and Maxillofacial Surgeons of India 
Disadvantages of flaps include:

- Their cost in resources and expertise.

- Increased operative time.

- Donor site morbidity.

- The risk of partial or complete failure.

\subsubsection{Transplantation}

Over recent years a number of partial and total facial transplants have been performed successfully. These cases are rare, requiring extremely careful selection and require a huge amount of resources. When indicated, however, this may be the only option to provide a cosmetic and to some extent functional outcome. Additional factors not associated with other reconstructive techniques, including donor selection, psychology, ethics and long-term immunosuppression require thorough consideration.

\subsection{Reconstruction of the Oral Cavity}

The functional roles of the oral cavity are among the most important in the body and are extremely sensitive to alteration resulting from even an apparently small defect. The coordinated action of structures within a relatively small anatomical region are critical for both nutrition (mastication and deglutition) and social interaction (speech and facial expression), two of the most vital activities that determine a patient's quality of life.

\subsubsection{Reconstruction of the Lips}

The aim of lip reconstruction should be to restore both function and aesthetics. Careful reconstitution of lip anatomy, such as the white roll, vermilion border and Cupid's bow, are required for a satisfactory cosmetic outcome. Continuity of the orbicularis oris muscle and adequate perioral sensation are needed to maintain lip competence. This is important during mastication and the oral stage of deglutition, particularly with fluids, and to prevent drooling in repose. The size of the reconstructed oral aperture will affect function too. All of these factors will contribute to the aesthetics of the lower third of the face.

The lips are unique in that they represent the transition from cutaneous tissue to keratinized dry and non-keratinized wet mucosa. As a result reconstruction of lip defects is best achieved by using remaining lip tissue when possible. This also often preserves contiguous, innervated orbicularis oris muscle and hence function as explained above.
Table 86.3 Time line of lip reconstruction techniques

\begin{tabular}{|c|c|c|}
\hline Year & Author & Technique \\
\hline $1000 \mathrm{BC}$ & Shushruta & First mention of lip repair \\
\hline $1597 \mathrm{AD}$ & Tagliacozzi & $\begin{array}{l}\text { Upper and lower lip repair using forearm } \\
\text { flap }\end{array}$ \\
\hline 1768 & Louie & Wedge excision described \\
\hline 1838 & Sabattini & Full-thickness switch from lower to upper \\
\hline 1845 & Dieffenbach & Cheek advancement for upper lip repair \\
\hline 1857 & Von Bruns & Cheek advancement for lower lip repair \\
\hline 1872 & Estlander & Upper to lower switch at commissure \\
\hline 1898 & Abbe & Lip switch for bilateral cleft lip \\
\hline 1909 & Lexer & Tongue flaps for lip repair \\
\hline 1954 & Schuchardt & Sliding inferiorly based cheek flaps \\
\hline 1969 & Bakamjian & Deltopectoral flap to lower lip defect \\
\hline 1974 & Karapandzic & $\begin{array}{l}\text { Advancement along nasolabial fold for } \\
\text { lower lip defects }\end{array}$ \\
\hline
\end{tabular}

Therefore, local rotational, advancement and cross-lip flaps have become mainstays of reconstruction for larger deformities not amenable to direct or sliding lip closure (Table 86.3).

\subsubsection{Reconstruction of the Vermillion}

Deformity of the vermillion and the white roll of the lips is readily apparent to most observers; therefore careful reconstruction is vital for cosmesis. Small superficial defects that do not involve the underlying orbicularis muscle may be left to heal satisfactorily by secondary intention, although the process is slow (25 days on average) and can result in contracture $[5,6]$. For these reasons, primary closure of a small vertically oriented fusiform excision is the preferred option, especially as often the defect will extend just beyond the vermillion, so control of the vermillion border re-approximation is required. Where redundant 'dog ear' mucosal tissue is likely to occur with primary closure of a mucosa only defect, a V-Y island of mucosa can be advanced from the labial mucosa or laterally from adjacent vermillion [7].

Large superficial defects of the upper or lower vermillion are best managed by resection of the entire vermillion subunit (lip shave) and advancement of a flap of labial mucosa. This provides a close cosmetic match, particularly in older patients. Sensation often returns with this approach; however, atrophy and contracture can be apparent particularly if the depth of the flap is not matched carefully to the depth of the defect. Alternatively, transfer of the vermillion of the opposing lip has been described, either as a single or bi-pedicled mucosal flap. Underlying muscle can be included as a myomucosal flap pedicled on the labial vessels [8]. These approaches require division and inset as a second procedure, arguably for minimal benefit compared with mucosal advancement from the labial mucosa. Reconstruction with tongue [9], buccal mucosal or myomucosal flaps can give 
acceptable results. Finally, anal verge mucosa grafts to the lips has also been described [10].

\subsubsection{Reconstruction of the Lower Lip}

\subsubsection{Defects Up to one Half of Lower Lip Width}

Depending on the laxity of the lower lip, which is mainly related to the age of the patient, most defects of less than one third to half the width of the lower lip can be closed primarily with excellent cosmetic and functional outcomes. The defect is extended inferiorly along a ' $v$ ' or shield shape incision. The point of the ' $v$ ' can be curved laterally to follow the labiomental groove to camouflage the scar in wider defects. In even larger defects, this groove can be followed on one or both sides of the base of the resection to aid in tissue mobilization. Some surgeons utilize a ' $w$ '-shaped incision at the base of the defect, but this may result in a less cosmetic scar. Defects that involve the commissure can be more challenging as blunting that results may require a further commissuroplasty procedure.

\subsubsection{Defects Greater Than One Half Lower Lip Width}

Lower lip defects of this proportion are unlikely to be able to be closed primarily without causing unacceptable microstomia.

\section{Lip Switch Flaps}

A reverse Abbe flap (see upper lip reconstruction below) can be used to reconstruct larger lower lip defects, whereby a segment of upper lip with the same vertical dimension, but around $50 \%$ of the width of the lower lip defect is pedicled laterally on the labial artery. To prevent deformity of the upper lip, harvest should only be from lateral to the philtrum. In theory bilateral reverse Abbe flaps can be used, although the two pedicles that result make oral intake difficult until the flaps are inset.

\section{Karapandzic Flap}

The Karapandzic flap allows reconstruction of lower lip defects up to $80 \%$ of the lower lip width [11], with good preservation of function and aesthetics (Fig. 86.4). Some degree of microstomia and blunting of the commissures is caused, however. Unilateral or bilateral transdermal curvilinear incisions that follow the nasolabial creases allow mobilization and re-approximation of the remaining lower lip [12]. The incision extends through dermis only, preserving the neurovascular supply to the remaining lower lip either side of the defect. This is the main advantage compared with the older advancement flaps such as the Gillie's fan flap (Fig. 86.5), which disrupt underlying neurovasculature due to full-thickness incisions.

\subsubsection{Subtotal Defects}

\section{Cheek Advancement Flaps}

Bilateral horizontal cheek advancement flaps where described by Bernard (1852) and von Burow (1853) for reconstruction of large lip defects [13]. Tissue is advanced from the cheek by extending incisions laterally from the commissure and excising three triangles - two lateral Burow's triangles and one triangle around the defect of the lower lip itself. Webster refined this technique for reconstruction of lower lip defects using only partial-thickness incisions along the nasolabial and labiomental creases [14] (Figs. 86.6, 86.7 and 86.8). This concept was further refined
Fig. 86.4 Bilateral Karapandzic flaps for reconstruction of lower lip defect
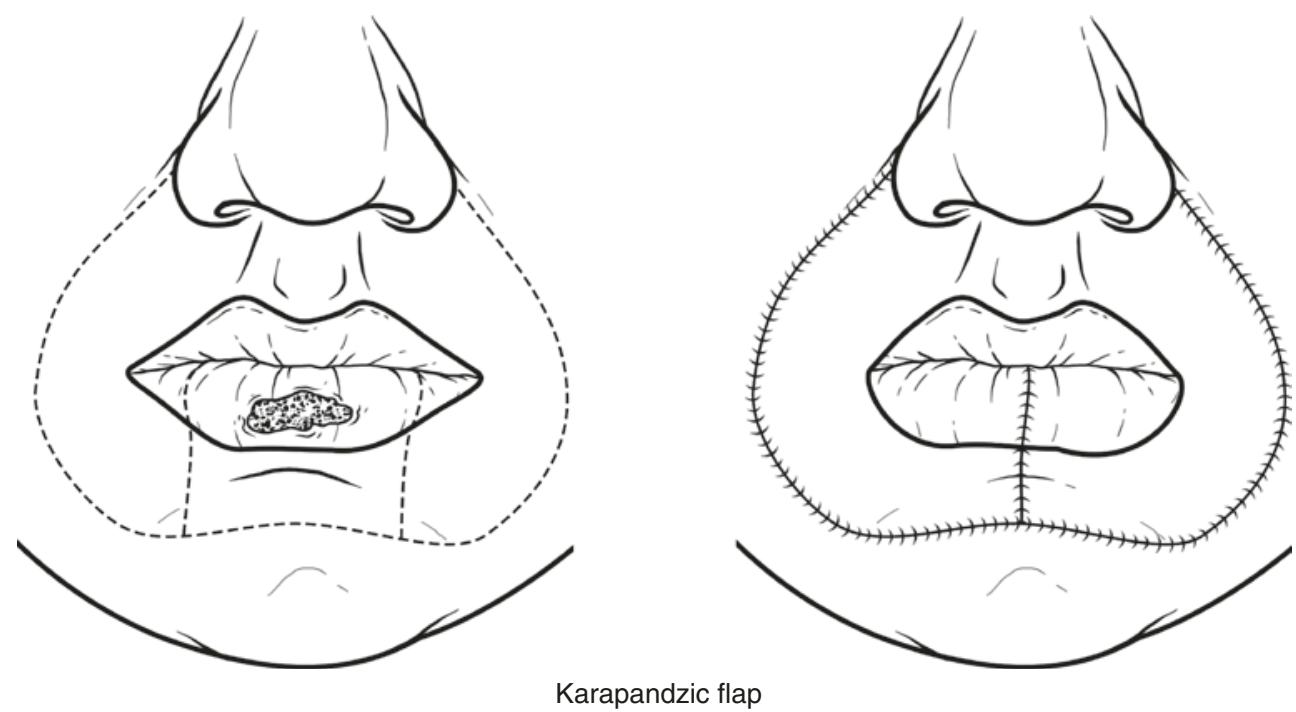

CAssociation of Oral and Maxillofacial Surgeons of India 
Fig. 86.5 Gillies fan flap for reconstruction of lower lip defects

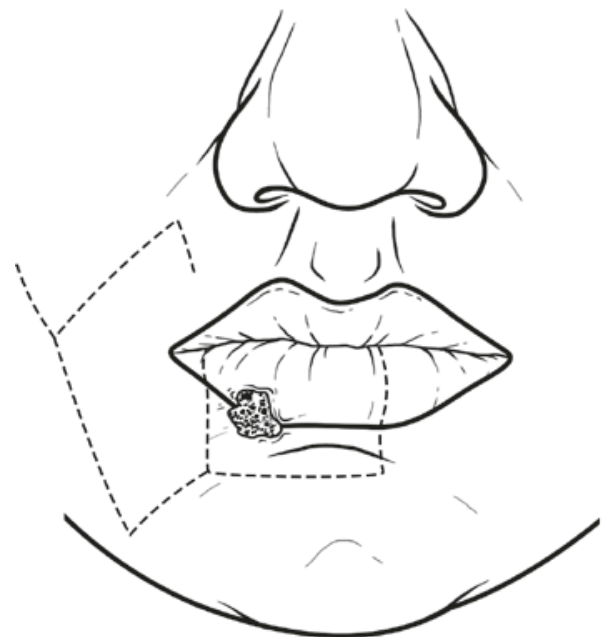

Gillies fan flap

(C)Association of Oral and Maxillofacial Surgeons of India

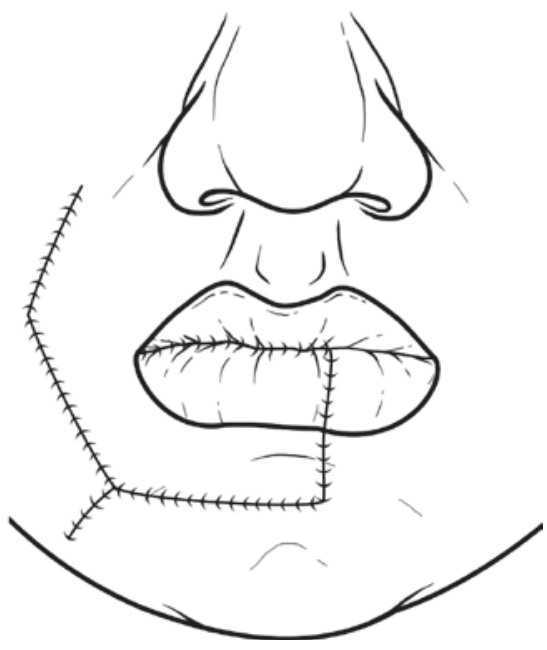

Fig. 86.6 Webster modification of Bernard-von Burow flap for lower lip reconstruction
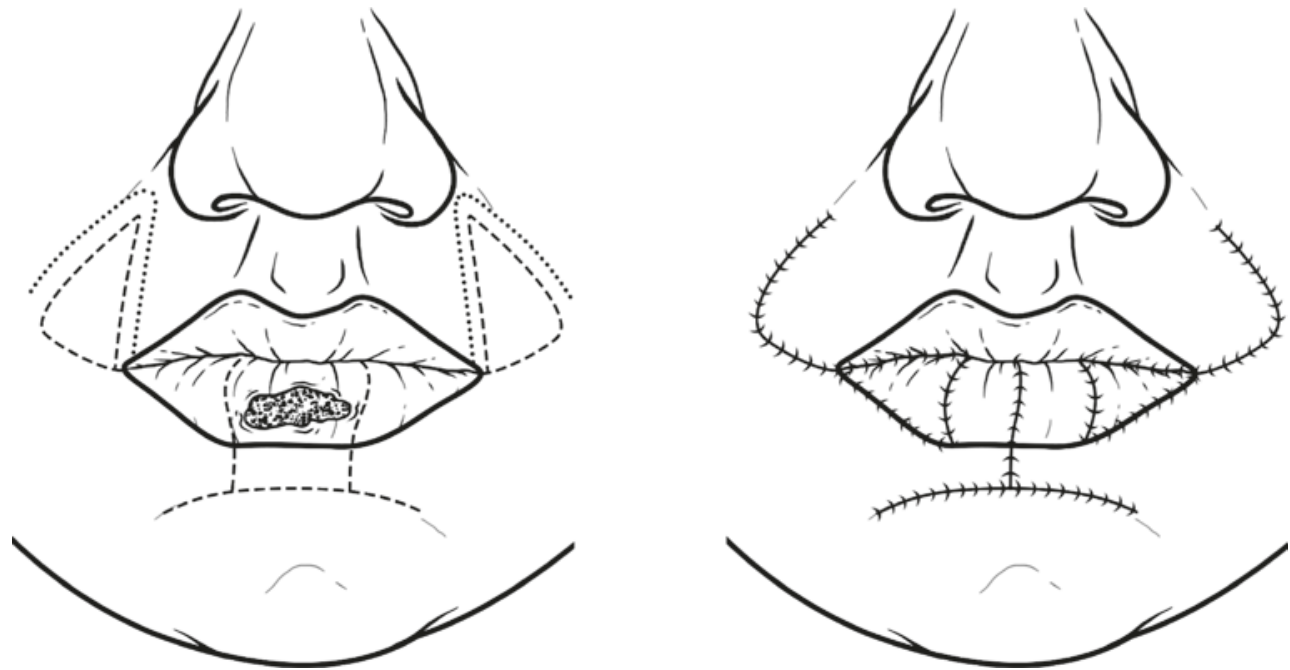

Bernard von burrow flap

(C)Association of Oral and Maxillofacial Surgeons of India

by Pirgousis and Fernandes for lower lip reconstruction [15] (Figs. 86.9 and 86.10).

\section{Nasolabial Flaps}

Fujimori described 'gate' flaps that are effectively nasolabial flaps, which can be combined with a lower labial mucosa advancement flap to reconstruct the entire lower lip [16]. A similar technique allows reconstruct of the upper lip [17] (Fig. 86.11).

\subsubsection{Reconstruction of the Upper Lip}

\section{Primary Closure}

Defects of the upper lip are less amenable to primary closure than those of the lower lip. There is relatively less laxity, and asymmetry is more apparent because of deviation or distor- tion of the philtrum and nasal base. Defects up to around one quarter to one third of upper lip width can still be reapproximated satisfactorily, particularly if laterally situated. The philtrum is less forgiving though and while defects up to around half the width can be closed primarily, there is a tendency for flattening and upwards retraction of the vermillion in this subsite.

\section{Lip Switch Flaps}

The first report of a two-stage pedicled 'lip switch' flap was by Sabattini in 1838 [18]. The labial artery-based flap was popularized by Abbe in 1898, however, for use in cases of bilateral cleft lip [19]. The lower lip donor site is designed to be half the width of the upper lip defect (to equalized the horizontal discrepancy between upper and lower lips), equal to the height of the defect, and with a laterally based pedicle. 


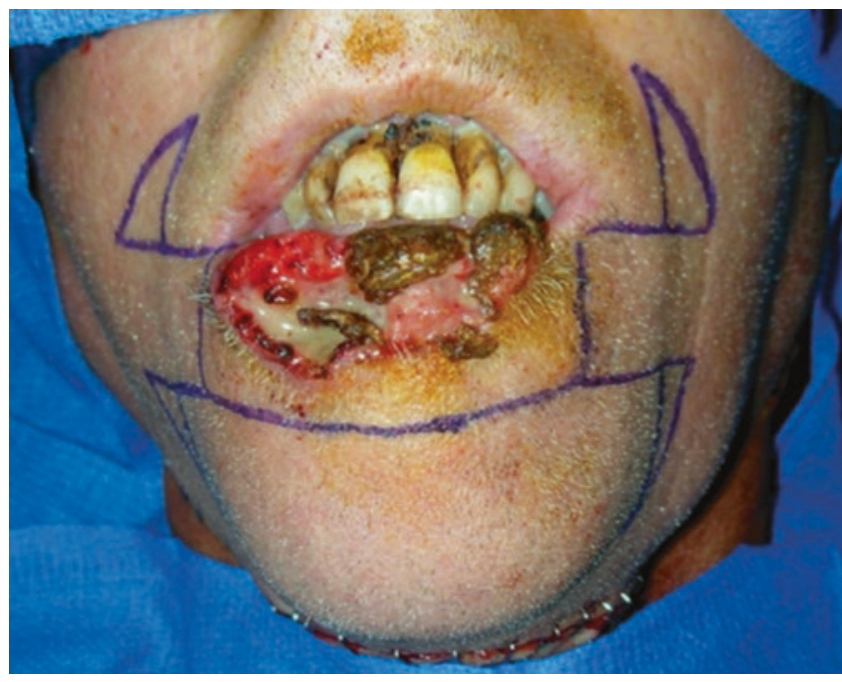

CAssociation of Oral and Maxillofacial Surgeons of India

Fig. 86.7 Webster-Bernard-Burrow flap markings prior to lower lip resection

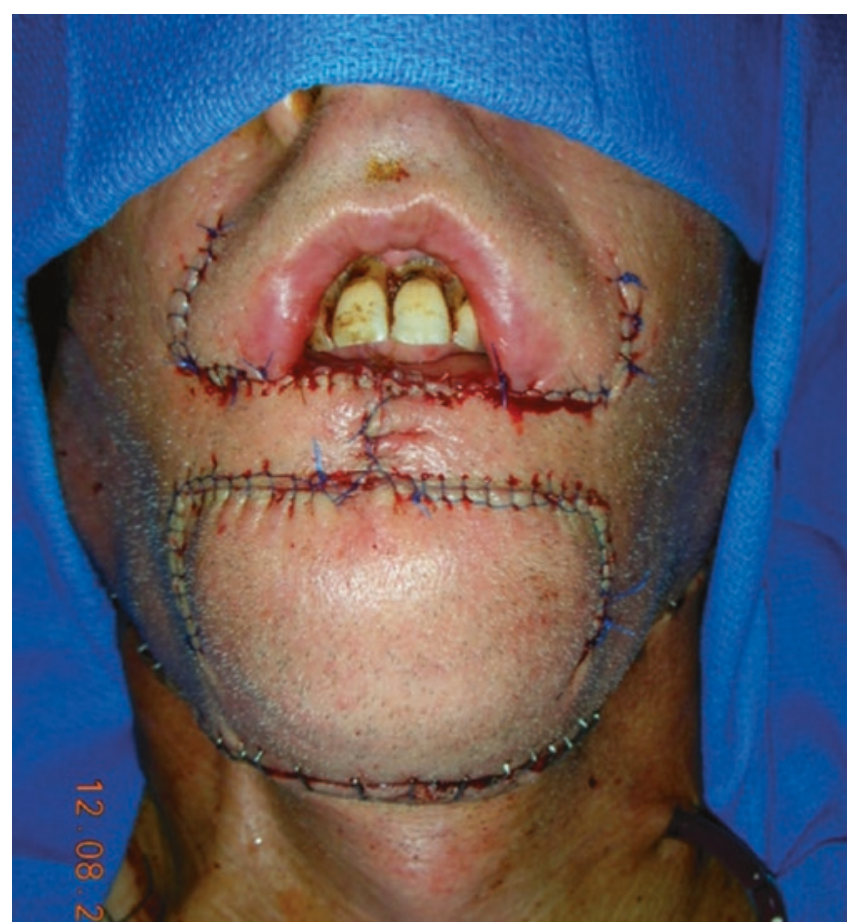

CAssociation of Oral and Maxillofacial Surgeons of India

Fig. 86.8 Webster-Bernard-von Burow flap following closure

The central lower lip is the preferred donor site, as it is hairbearing in males and leaves the least prominent scar. The white roll should be marked prior to incision and potential obscuration due to bleeding, oedema and pallor. The flap is raised including skin, muscle and mucosa but with preservation of the lateral vermilion incorporating the labial vessels. The flap is rotated and inset, taking care to re-approximate

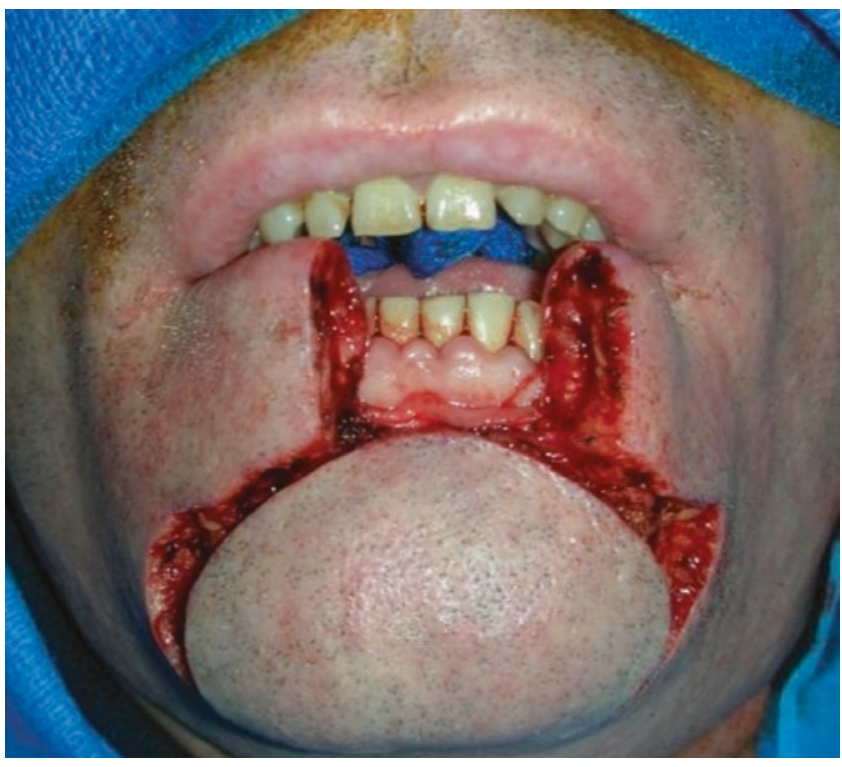

CAssociation of Oral and Maxillofacial Surgeons of India

Fig. 86.9 Fernandes flap incisions following lower lip resection

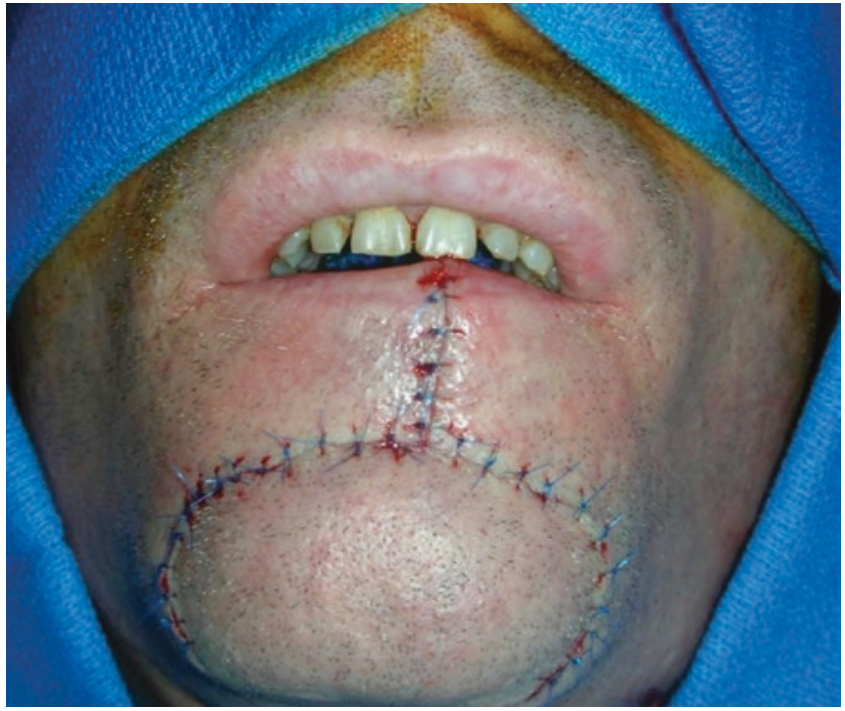

CAssociation of Oral and Maxillofacial Surgeons of India

Fig. 86.10 Fernandes flap following closure

the orbicularis oris muscle and align the white roll (Fig. 86.12). After 2-3 weeks, the pedicle is divided and the flap inset. For defects of the commissure, Estlander described a similar flap where the commissure is the rotation point, and therefore no secondary insetting is required (Fig. 86.13).

\section{Perialar Crescentic Advancement}

Initially described by Webster [20], a perialar incision can be made unilaterally or bilaterally to recruit lateral tissue for closure of upper lip defects (Figs. 86.14 and 86.15). This technique can also be combined with an Abbe flap to recon- 
Fig. 86.11 Bilateral nasolabial flaps for lower lip reconstruction
Fig. 86.12 Abbe flap for upper lip reconstruction. (a) Defect and flap markings. (b) Flap inset prior to division of pedicle
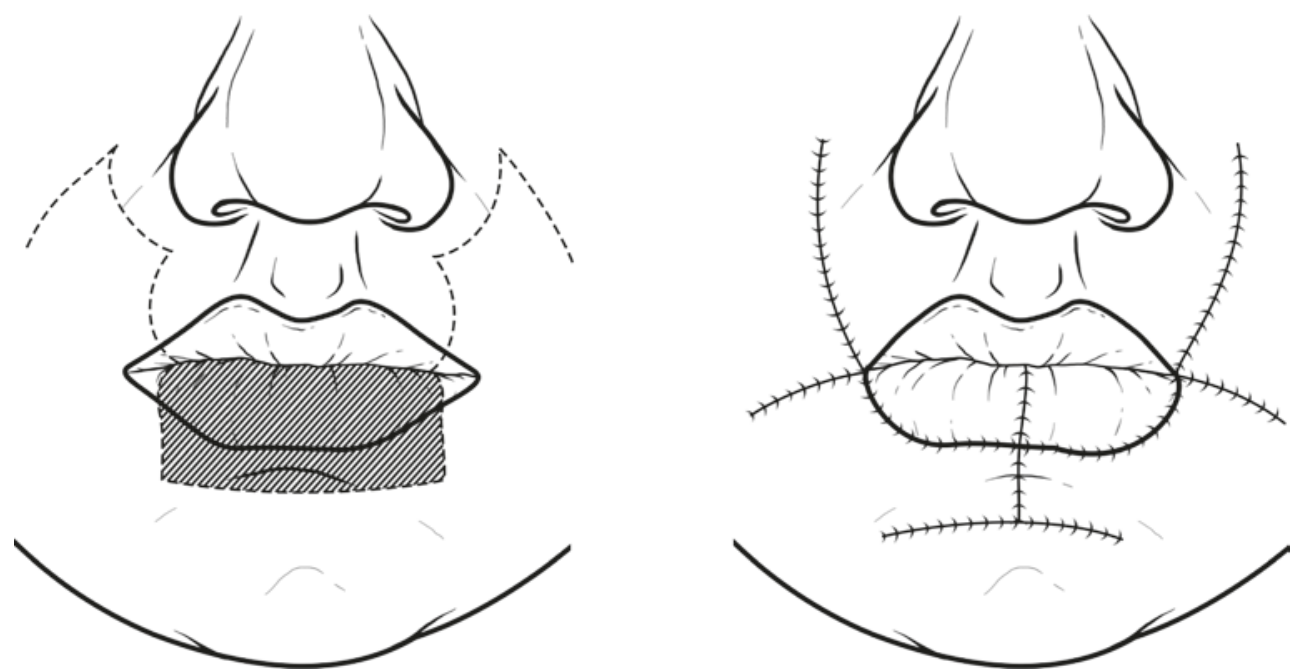

Nasolabial (von bruns) flap

(C)Association of Oral and Maxillofacial Surgeons of India

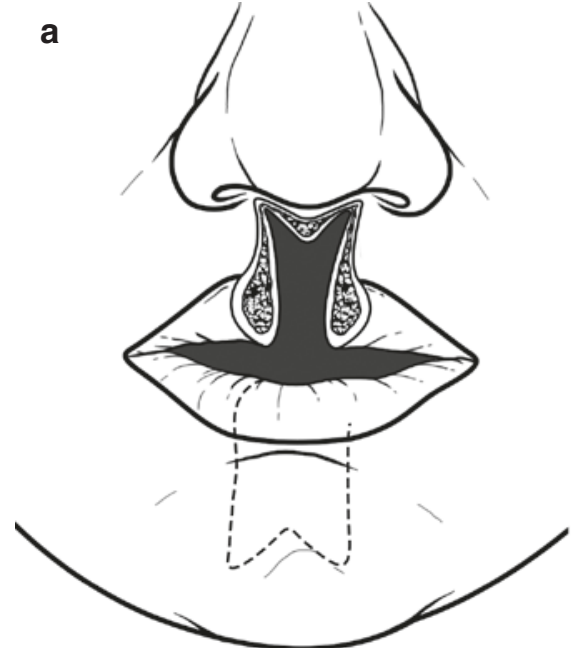

b

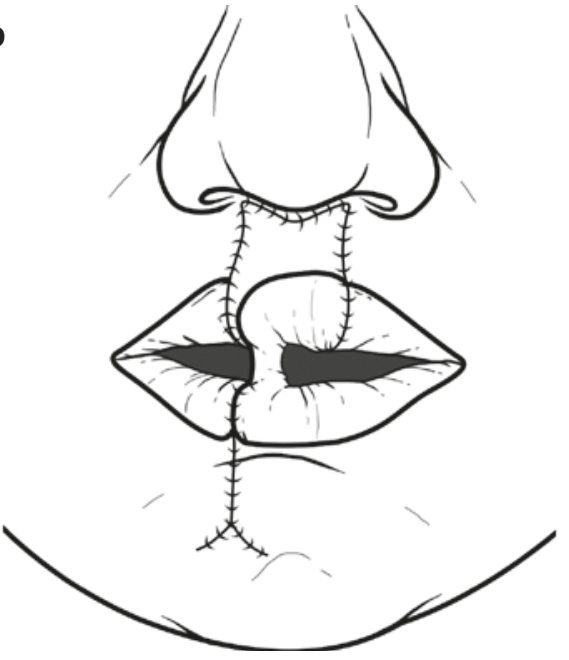

(C)Association of Oral and Maxillofacial Surgeons of India struct the philtrum when defects involve the midline of the upper lip.

\section{Reverse Karapandzic}

Incisions following the melolabial groove upwards to join the superior margin of an upper lip defect can be used to advance lateral tissue in a similar fashion as the Karapandzic flap does for closure of lower lip defects.

\subsubsection{Commissuroplasty}

Most of the reconstructive techniques described above result in blunting and rounding of the oral aperture. The simplest way to correct this is to make a horizontal full-thickness incision through the blunted commissure, extending laterally to correspond with the position of the contralateral normal commissure. Epithelium superior and inferior to the incision is excised and labial mucosa advanced from intraorally to recreate the vermilion (Fig. 86.16). An alternative method was described by Gillies and entails excision of a triangular segment of skin lateral to the rounded commissure, to a point comparable with the normal side. A vermilion flap from the opposite lip is then raised and rotated into this and a mucosal flap advanced to reconstruct the vermilion of the donor site (Fig. 86.17).

\subsubsection{Total Lip Defects}

A combination of the techniques presented above can be employed to reconstruct total defects of one or other lip. Increasingly, free tissue transfer is used instead, however. The most commonly used flap for this purpose is the radial free flap (Figs. 86.18 and 86.19). This is mainly due to the thin, soft, pliable tissue offered and reliable, long pedicle. 
Fig. 86.13 Estlander flap for reconstruction of defect involving commissure. A medially pedicled fullthickness flap half the width of the defect is raised from the upper lip and inset into the lower lip defect
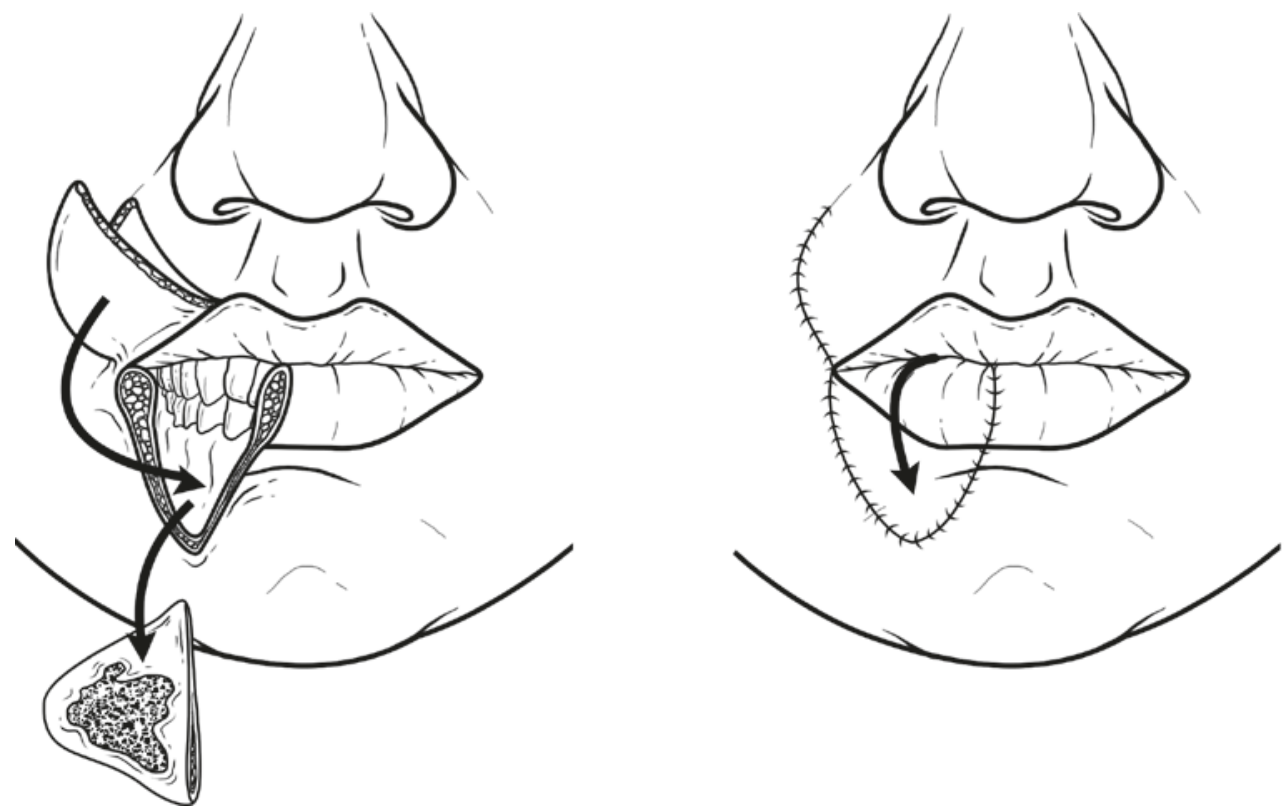

(C)Association of Oral and Maxillofacial Surgeons of India

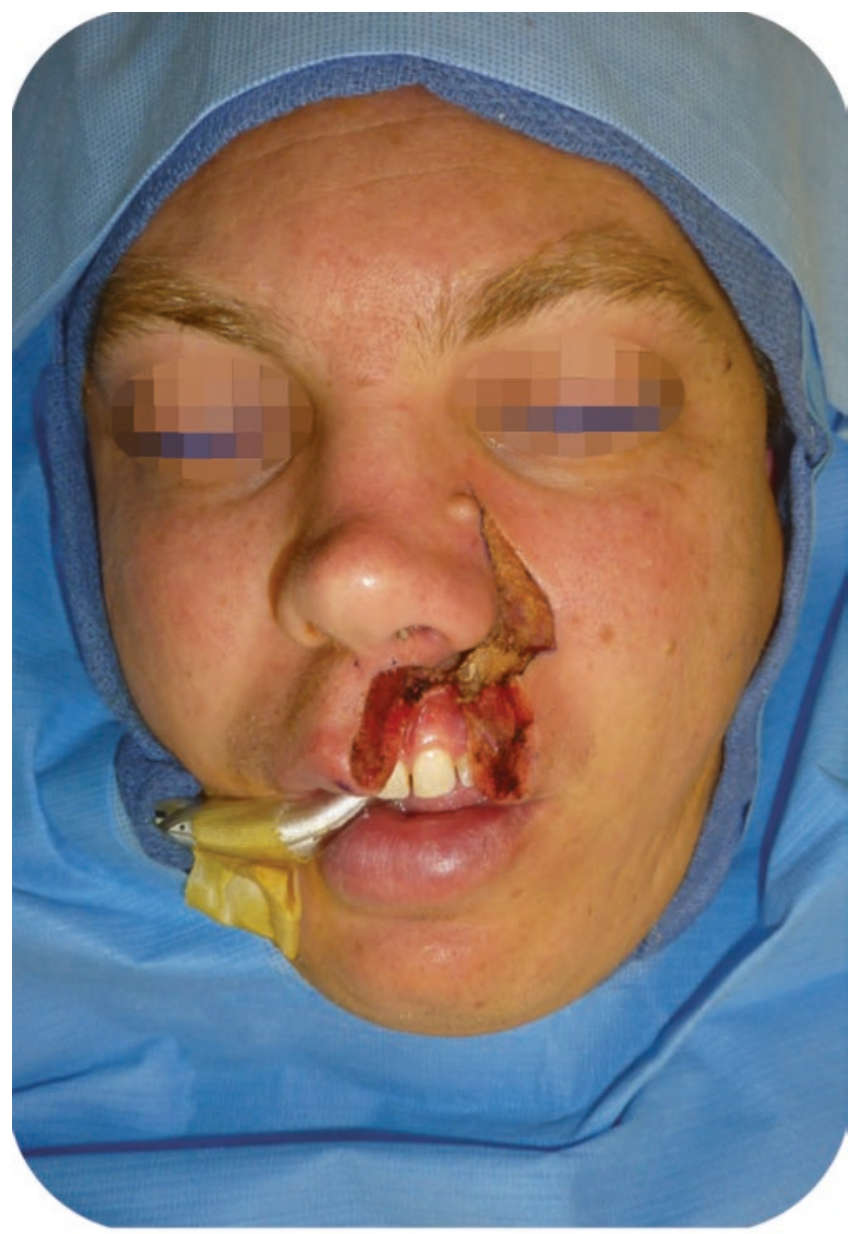

CAssociation of Oral and Maxillofacial Surgeons of India

Fig. 86.14 Perialar crescentic flap to reconstruct upper lip defect

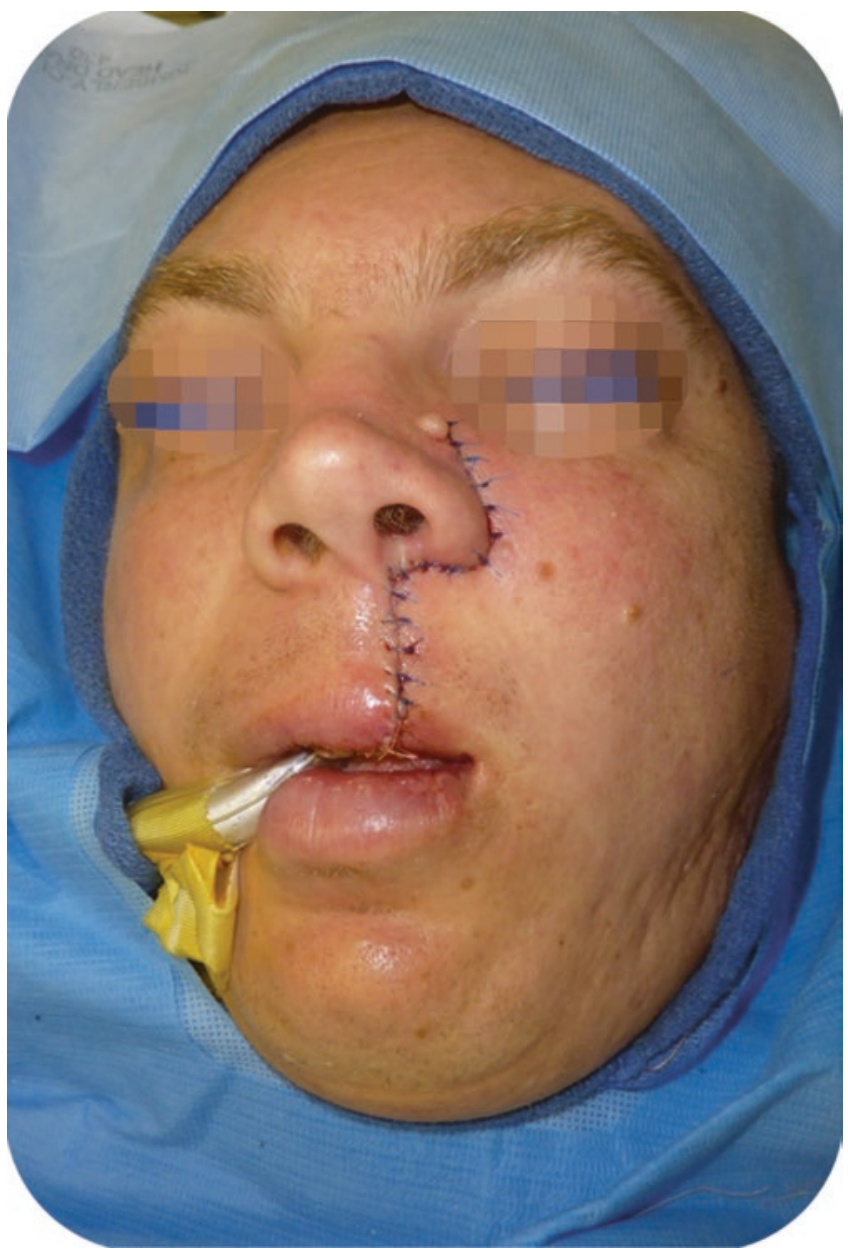

CAssociation of Oral and Maxillofacial Surgeons of India

Fig. 86.15 Perialar crescentic flap after closure 
Fig. 86.16 (a-d) Commissuroplasty. A full thickness incision is made through the blunted commissure and an area de-epithelialised to mirror the normal side (dashed lines, a). This is then re-surfaced with mucosal flaps raised from intraorally (b-d)

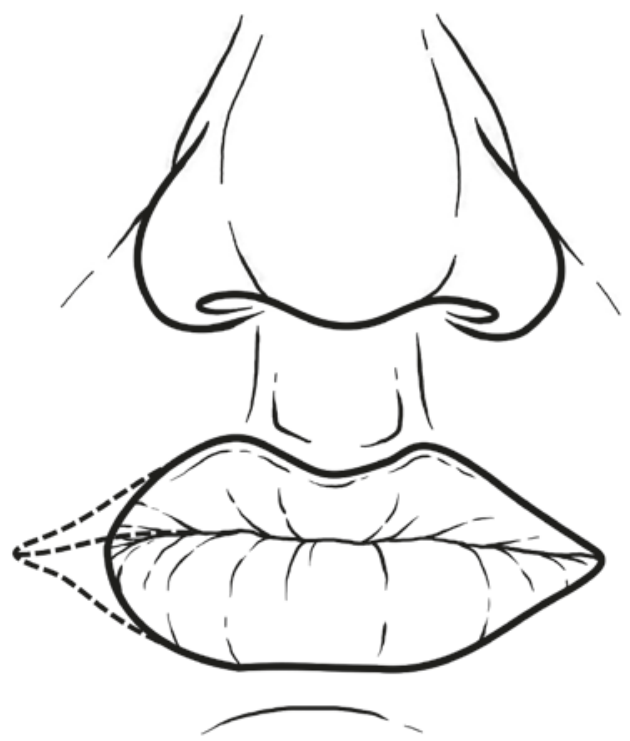

b
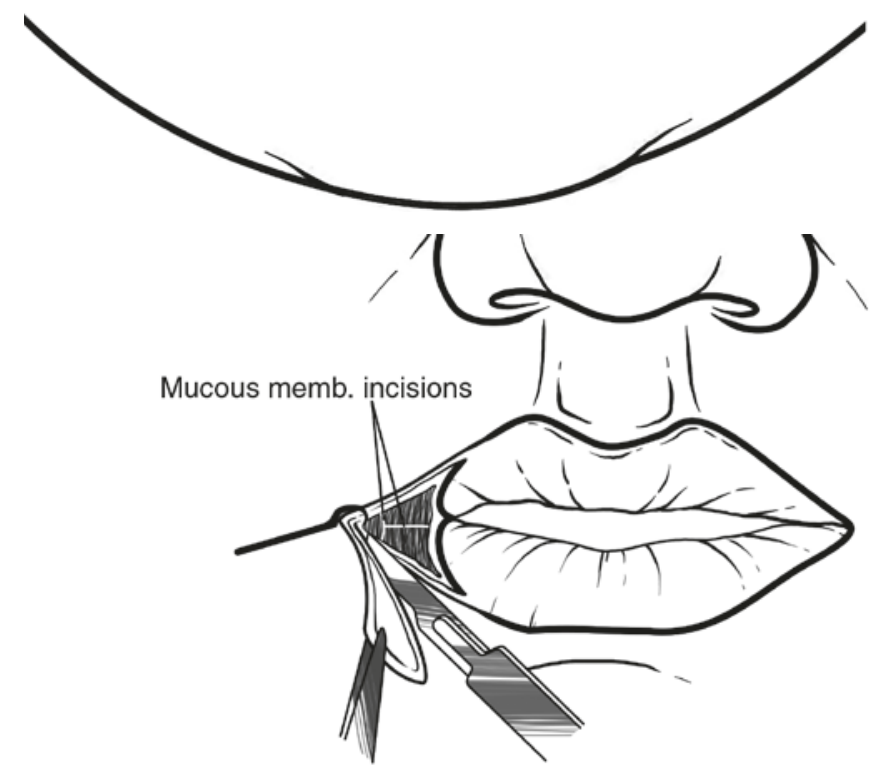

c

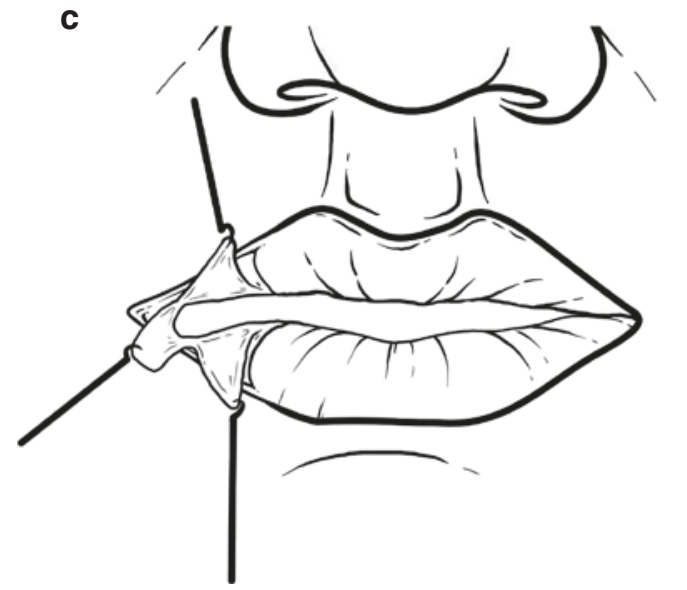

d

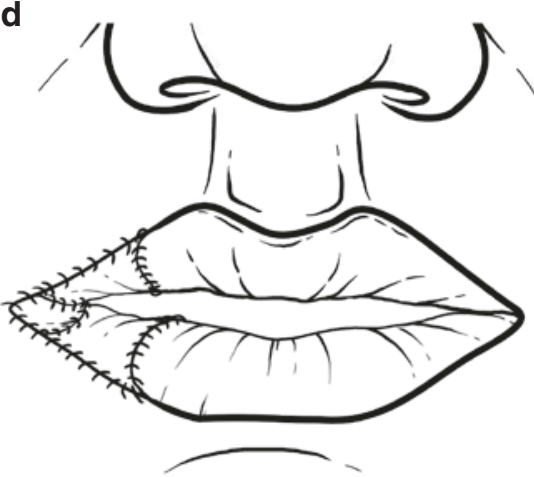


Fig. 86.17 (a-c) Gillies commissuroplasty. An area mirroring the normal commissure is de-epithelialised (dashed lines, a). Vermillion is raised from the lower lip and inset into the de-epithelialised upper lip (a, b). The lower vermillion is reconstructed with a mucosal flap raised from the labial mucosa $(\mathbf{b}, \mathbf{c})$ a

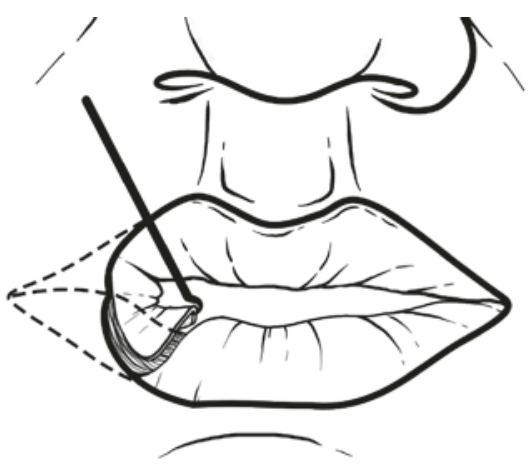

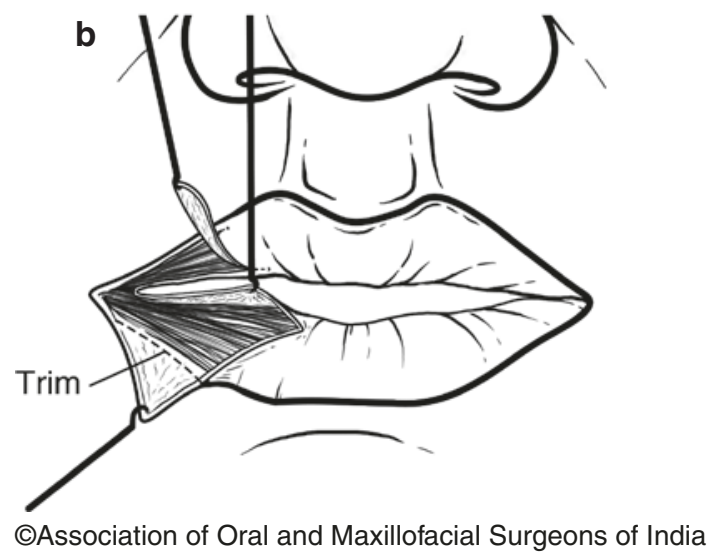

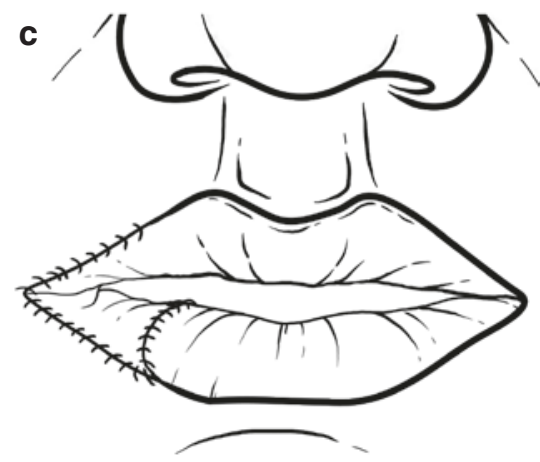

There is also the option to include palmaris longus tendon harvest [21]. This can be used as a sling between the commissures, or to the malar periosteum to improve lip form and oral competence. Alternatively, the flexor carpi radialis tendon or a nonvascularized fascia lata graft can be utilized for the same purpose. Coaptation of the lateral antebrachial cutaneous nerve to the mental nerve has been described to restore sensation to radial flap reconstruction of the lower lip [22]. Other free flaps that have been employed for total lip reconstruction include the gracilis for the lower lip [23-25] and temporal scalp for upper lip defects [26, 27].

\subsection{Buccal Mucosa and Cheek}

The main function of the cheek is to hold food between the occlusal surfaces of the teeth during mastication. Inadequate reconstruction can lead to excess tissue that interferes with mastication or insufficient tissue and scarring that results in trismus. Where possible the parotid duct should be repaired and/or re-sited in the buccal mucosa if involved in the defect or reconstruction to prevent obstructive parotitis. Small buccal mucosa defects can be closed primarily, but larger mucosal defects often benefit from reconstruction with a split-thickness skin graft or ipsilateral buccal fat pad [28]. As size and depth of the defect increases, the use of regional flaps described in the part of this chapter that addresses floor of the mouth defects should also be considered. The radial forearm flap is the most commonly used flap for reconstruction of intraoral buccal defects due to its pliability and lack of bulk (Figs. 86.20 and 86.21). Thicker and more extensive defects may benefit from an anterolateral thigh flap, depending on the patient's body habitus. Full-thickness cheek defects often require reconstruction of both the intraoral and extraoral surfaces. A combination of techniques may be employed, for example, a regional or free flap for the skin and a split-thickness skin graft for mucosa, but often it is best to consider reconstructing with a folded or dual paddled flap. Both radial forearm [29] and anterolateral thigh [30] free flaps are well suited for bi-paddled designs. The first is more pliable and thinner; the second can be made larger and confers less donor site morbidity, as it can generally be closed primarily. The portion between the paddles is deepithelialized where it will lie within the substance of the cheek. Alternatively, if the lip is involved in the defect, the intervening tissue can instead be used to reconstruct the lip. Obviously this will be a static repair and will therefore have an effect on oral competence.

Full-thickness cheek defects often involve the buccal or marginal mandibular branches of the facial nerve, with con- 

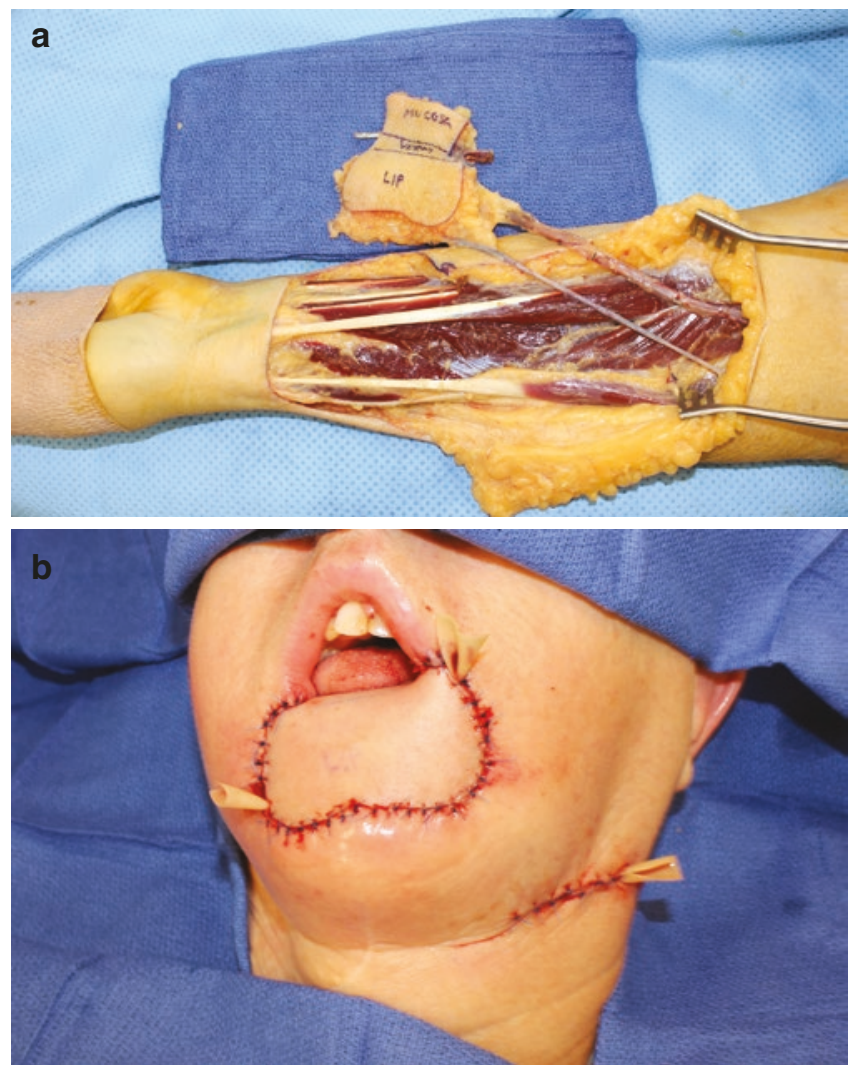

CAssociation of Oral and Maxillofacial Surgeons of India

Fig. 86.18 (a) Design of RFFF for lower lip reconstruction. (b) RFFF after inset to subtotal lower lip defect

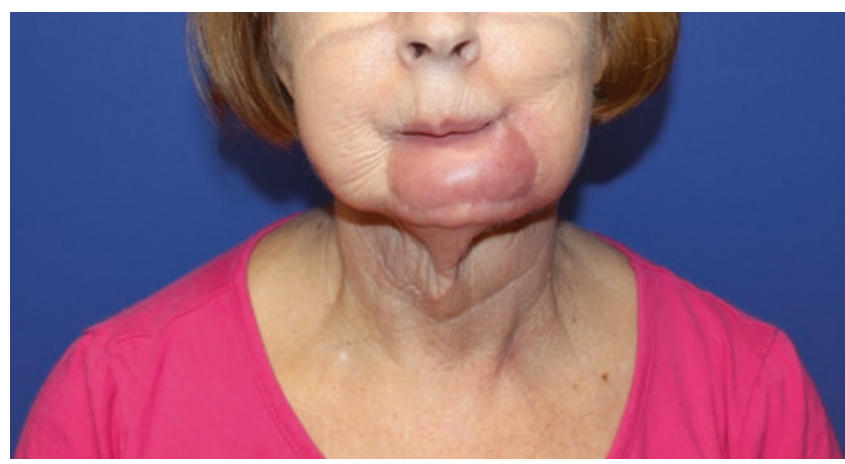

CAssociation of Oral and Maxillofacial Surgeons of India

Fig. 86.19 Late postoperative appearance of RFFF reconstruction of subtotal lower lip defect

sequent paralysis of the lower face. A detailed description of facial reanimation is outwith the scope of this chapter; however the methods can broadly be categorized as either static or dynamic. Static reanimation includes gold or platinum weights or springs to aid upper eyelid closure and resuspension of the oral commissure to deep temporal fascia with palmaris longus, fascia lata, acellular dermal matrix, PTFE or polypropylene [31]. Dynamic reanimation involves either

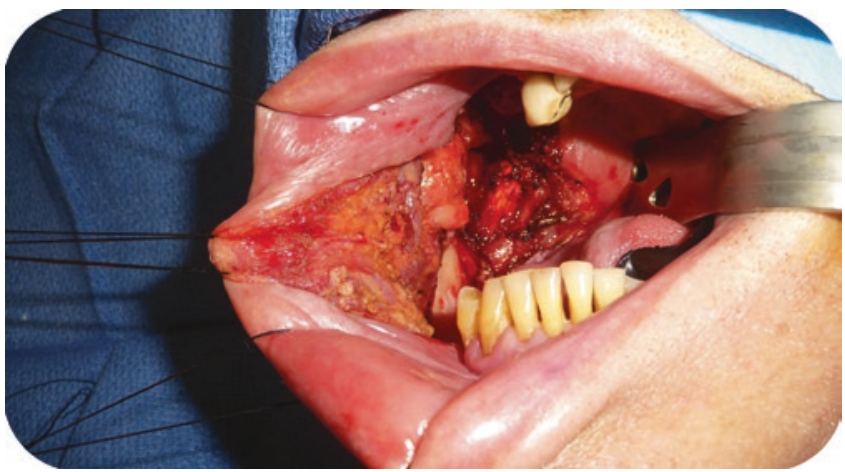

CAssociation of Oral and Maxillofacial Surgeons of India

Fig. 86.20 Buccal mucosa defect

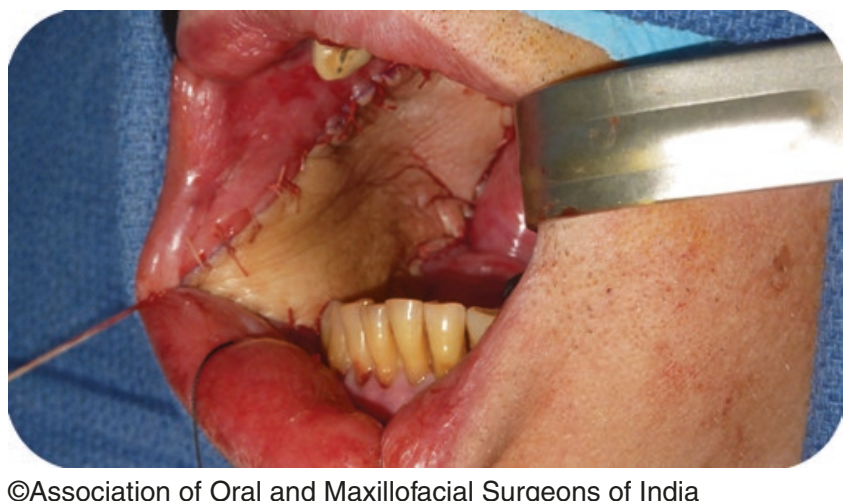

Fig. 86.21 RFFF inset to reconstruct buccal mucosa defect

the reinnervation, usually with nerve grafts or the interposition of innervated muscle, commonly temporalis transposition or a gracilis neuromuscular free flap [32].

\subsection{Floor of Mouth}

The floor of the mouth comprises the myomucosal diaphragm that extends from the ventral surface of the tongue, bounded anteriorly and laterally by the lingual aspect of the mandibular gingiva and posteriorly by the retromolar trigone. This inferior limit of the oral cavity provides a reservoir for food during mastication, while the muscles are also active during deglutition. The mylohyoid, geniohyoid and anterior digastric muscles raise the aerodigestive tract anterosuperiorly during swallowing, anchoring the tongue and increasing the diameter of the fauces. At rest the same muscles, particularly genioglossus, prevent upper airway compromise by posterior displacement of the tongue: an important consideration when reconstructing this region. Finally, mobility of the tongue during speech, mastication and swallowing depends on adequate anterolateral separation from the mandible, and therefore reconstruction should 
also aim to recreate the lingual sulcus and prevent ankyloglossia.

One commonly employed method to reconstruct floor of mouth defects is the submental artery island flap, first described by Martin et al. in 1993 [33]. It is easily raised with minimal donor site morbidity to provide a large and reliable paddle. The pedicle is up to $8 \mathrm{~cm}$ in length, and cutaneous dimensions up to $7 \times 18 \mathrm{~cm}$ can be harvested, sufficient to reconstruct most pure floor of mouth defects. It confers less donor site morbidity than the main alternative of a radial forearm flap; often there is even a cosmetic improvement in the patient's soft tissue profile. The main concern with the use of this flap is in the oncological setting is due to potential compromise of nodal dissection in level 1. In one small series, four of nine patients undergoing SIF suffered local or regional recurrence thought to be attributable to incomplete nodal harvest [34]. On the other hand, Howard et al. found that in 50 patients undergoing SIF, all with clinically negative level 1 nodes, none experienced recurrence attributable to the flap [35]. It is generally accepted that the flap is contraindicated in necks with clinically positive nodes, particularly in level I. A history of radiation is a relative contraindication, though good outcomes have been described despite this [36, 37]. Finally, since the submental vessels arise from the facial vessels, the flap cannot be performed in patients who have undergone a neck dissection with sacrifice of the facial vessels. In such patients or where tissue is required outside previous radiation fields, the infrahyoid island flap [38] is an alternative of similar size and character to the SIF. Supraclavicular island (Fig. 86.22) and pectoralis major flaps are also well-proven options that generally lie outside any previously operated or radiated field. They have broad pedicles, which unless skeletonized can introduce excess tissue into the defect or the tunnel from donor site. A radial forearm free flap may therefore be preferred, providing a thin, supple reconstruction with negligible pedicle bulk (Figs. 86.23 and 86.24).

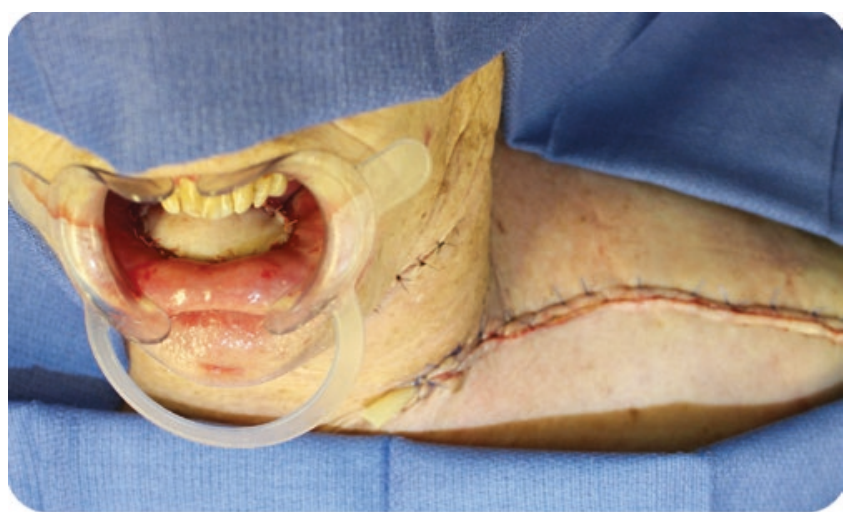

CAssociation of Oral and Maxillofacial Surgeons of India

Fig. 86.22 SCIF inset to reconstruct floor of mouth defect

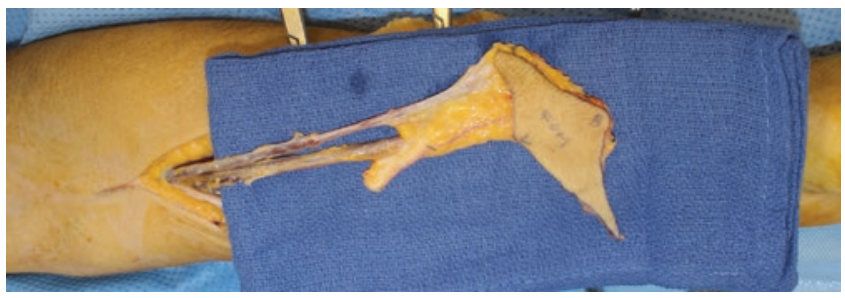

CAssociation of Oral and Maxillofacial Surgeons of India

Fig. 86.23 Design of RFFF for floor of mouth defect

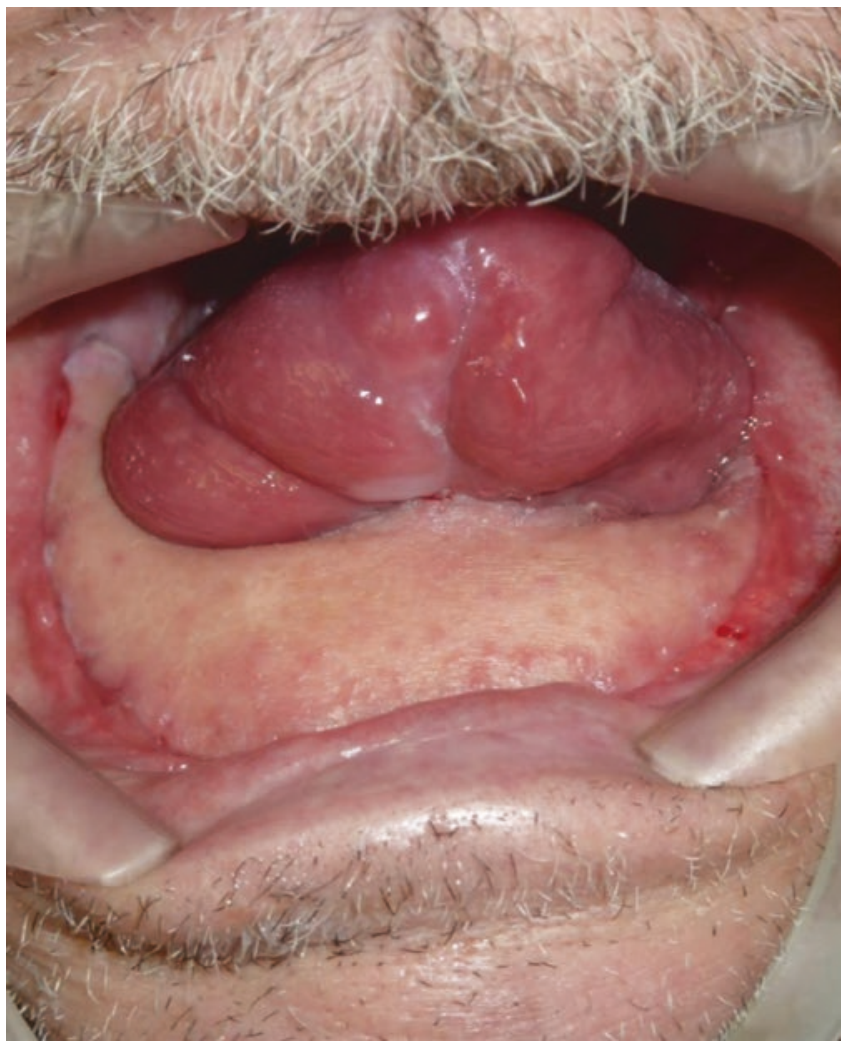

CAssociation of Oral and Maxillofacial Surgeons of India

Fig. 86.24 RFFF reconstruction of floor of mouth defect demonstrating good tongue mobility

\subsection{Tongue Reconstruction}

Adequate tongue function requires interaction between sensory and motor components of both voluntary and involuntary nervous systems to achieve intelligible speech, mastication and swallowing. Therefore tongue defects have a significant effect on quality of life compared with other oropharyngeal structures, proportional to their volume. Tongue reconstruction that recreates the biomechanics of the healthy tongue leads to better function and even cortical adaptation to the neotongue [39]. In terms of speech, the ability for the anterior tongue to contact the palate is particularly important. Speech therapy following tongue reconstruction should 
be considered as it can improve proprioception of the reconstructed tongue and facilitate cortical plasticity.

\subsubsection{Primary Closure}

Small volume defects of the free oral tongue can often be closed primarily with satisfactory outcomes (Figs. 86.25 and 86.26). As the area of the defect increases, the option of healing by secondary intention should be considered as this can result in a more natural tongue morphology, while dehiscence is often the natural course for primary closure in any case.

\subsubsection{Pedicled Flap Reconstruction}

Tongue defects can be reconstructed with a variety of pedicled flaps, often utilized when free tissue transfer is precluded. Prior to development of free tissue transfer, the pectoralis major and deltopectoral flap were common options, with the facial artery myomucosal flap an alternative for smaller volume defects. There has been a renaissance in the use of other regional flaps over recent years, such as the submental (Figs. 86.27 and 86.28), supraclavicular, trapezius and infrahyoid island flaps.

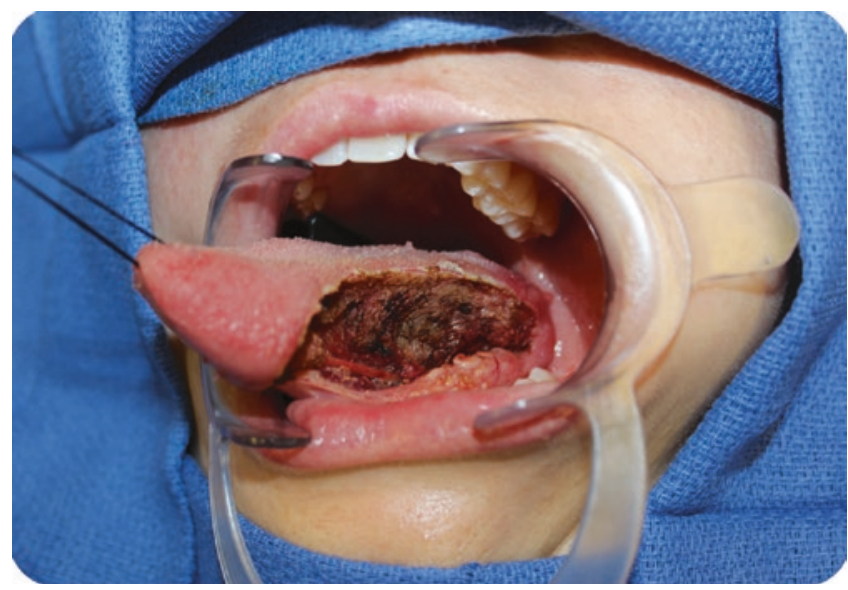

CAssociation of Oral and Maxillofacial Surgeons of India

Fig. 86.25 Superficial defect of lateral tongue

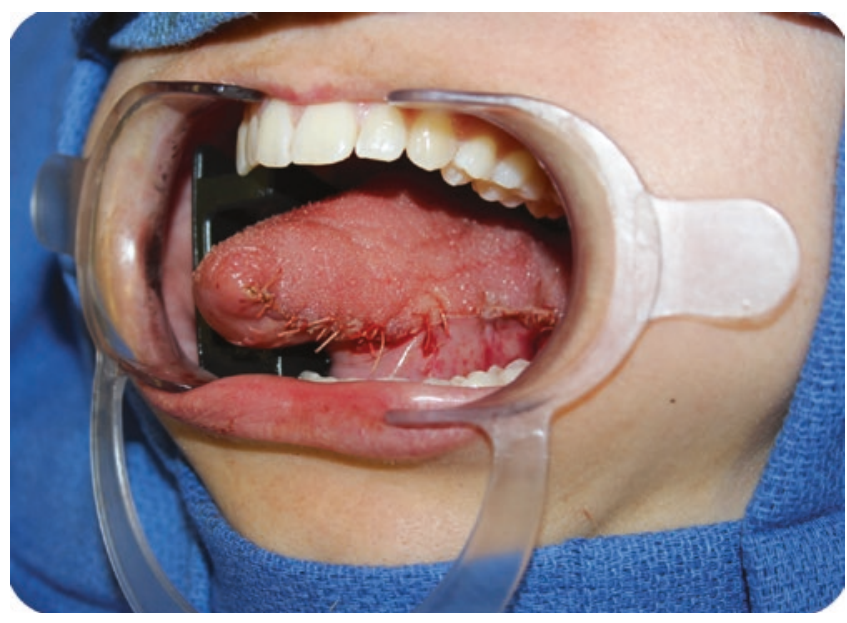

CAssociation of Oral and Maxillofacial Surgeons of India

Fig. 86.26 Primary closure of lateral tongue defect

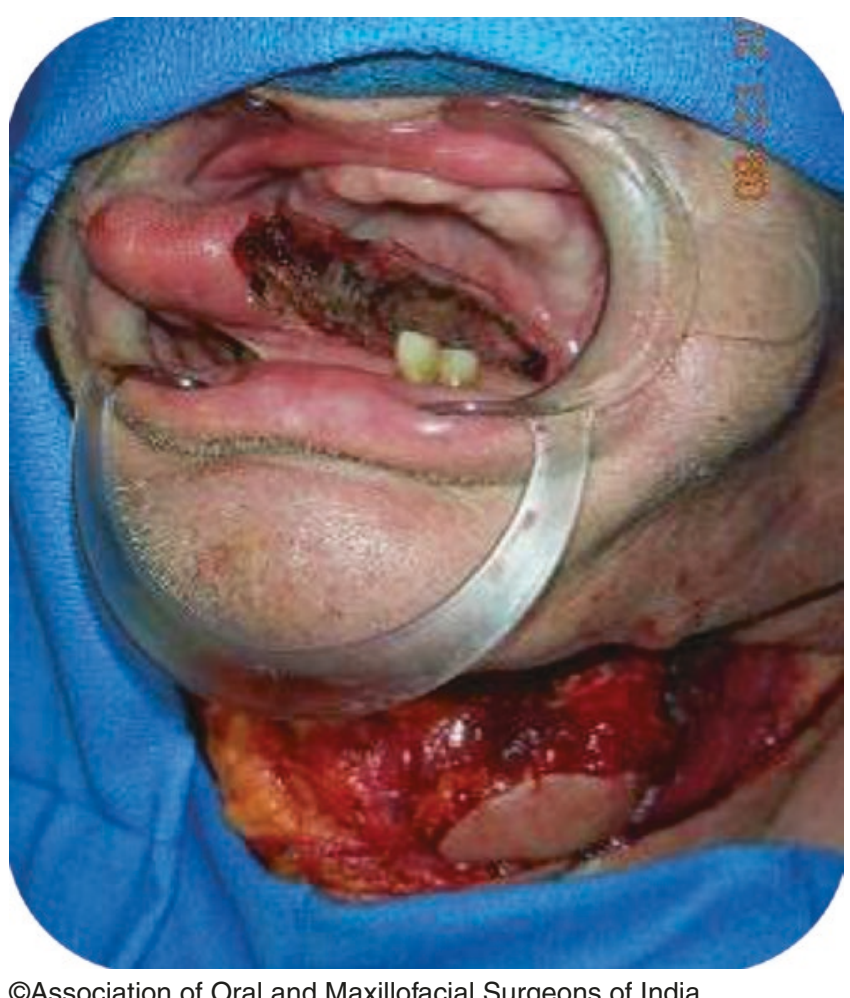

CAssociation of Oral and Maxillofacial Surgeons of India

Fig. 86.27 Submental flap prior to reconstruction of lateral tongue defect 


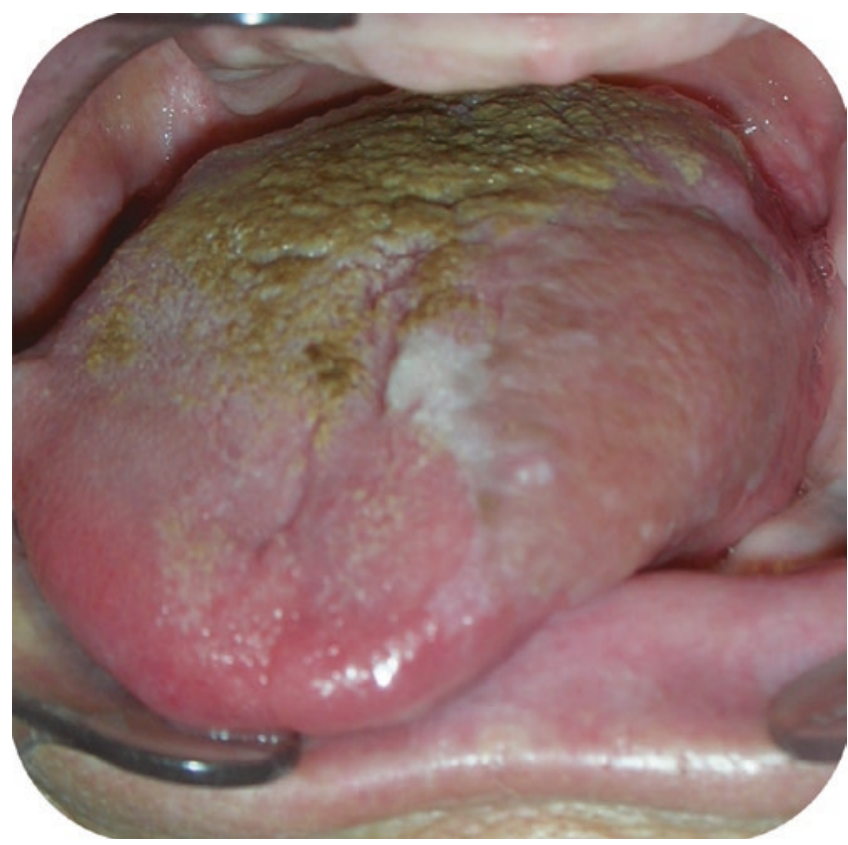

CAssociation of Oral and Maxillofacial Surgeons of India

Fig. 86.28 Late postoperative appearance of submental flap reconstruction of left lateral tongue

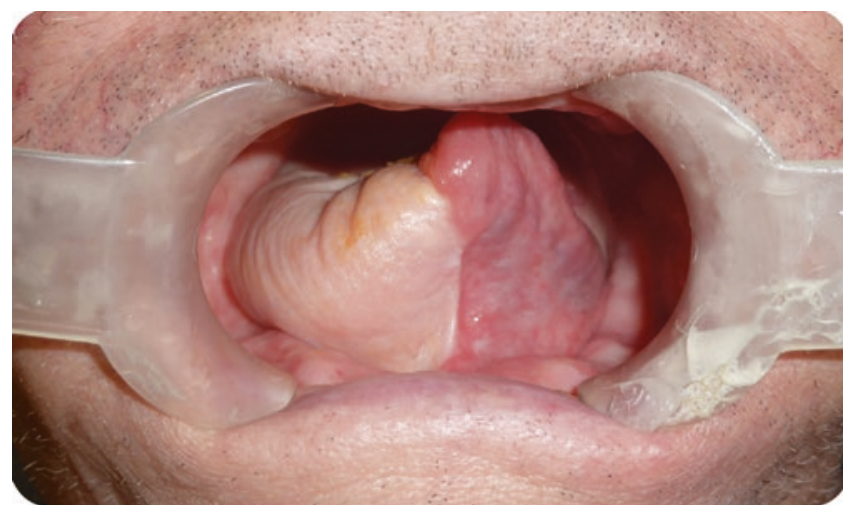

CAssociation of Oral and Maxillofacial Surgeons of India

Fig. 86.29 RFFF to reconstruct right hemiglossectomy

\subsubsection{Free Flap Reconstruction}

Tongue reconstruction with a microvascular free flap is usually recommended to restore form, resist contractures and tethering in defects greater than a quarter of the original tongue size [40]. The flap should be designed to recreate premorbid morphology in all three dimensions as far as possible.

The radial forearm free flap is the workhorse of tongue reconstruction for good reason (Fig. 86.29). It provides thin, pliable, soft tissue and large-calibre vessels of consistent

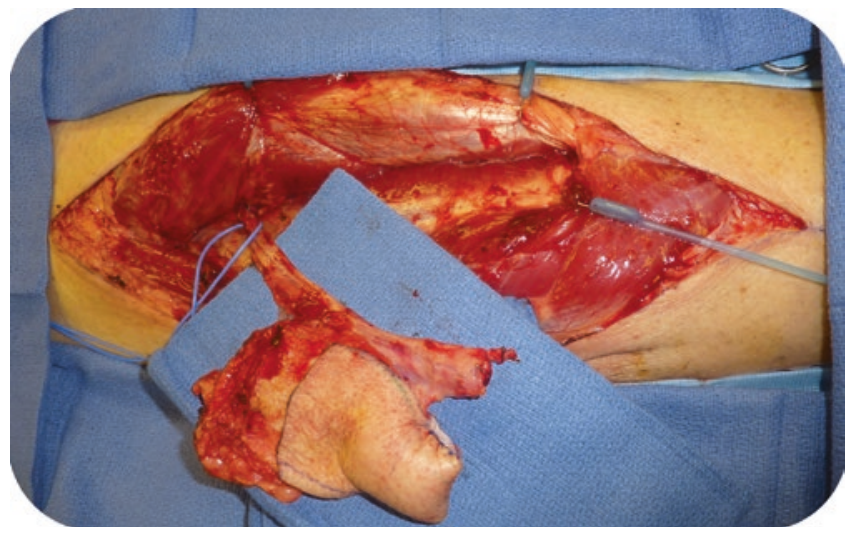

CAssociation of Oral and Maxillofacial Surgeons of India

Fig. 86.30 Folded ALT flap for glossectomy reconstruction prior to pedicle division

anatomy and excellent length for microvascular anastomosis. Harvest can be simultaneous with resection and presents limited morbidity. The lateral antebrachial cutaneous nerve can be coapted to the lingual nerve to provide a sensate flap with some evidence of improved function and resistance to atrophy [41]. Defects greater than three quarters of the tongue may benefit from reconstruction with tissue of greater substance such as an anterolateral thigh (ALT) or rectus abdominis free flap. ALT harvest results in a more easily hidden scar and potential sensory loss is less troublesome. Total glossectomy reconstruction is particularly challenging. Recreation of three-dimensional morphology is critical, with emphasis on height and a tip protruberance, to facilitate speech and swallowing [42] (Figs. 86.30 and 86.31). A flap that is around one third greater than the defect is recommended to achieve this aim due to inevitable atrophy. Hyolaryngeal suspension should also be considered as an adjunct, to reduce the risk of persistent laryngeal aspiration [43].

\subsection{Palatal Soft Tissue Defects}

Simple mucosal defects overlying the hard palate can be left to close by secondary intention. Although the process is sometimes prolonged, pain and remucosalization can be aided by an acrylic cover plate retained by bone screws or dental cribs. Buccal mucosa with or without buccal fat pad can be advanced to repair palatal mucosa if the adjacent alveolus is edentulous. Palatal mucosal flaps, facial artery myomucosal flaps, temporalis or temporoparietal flaps and tongue flaps are alternatives. Functional reconstruction of the soft palate is difficult, but uvula, posterior pharyngeal wall or folded radial free flaps are options to consider. 


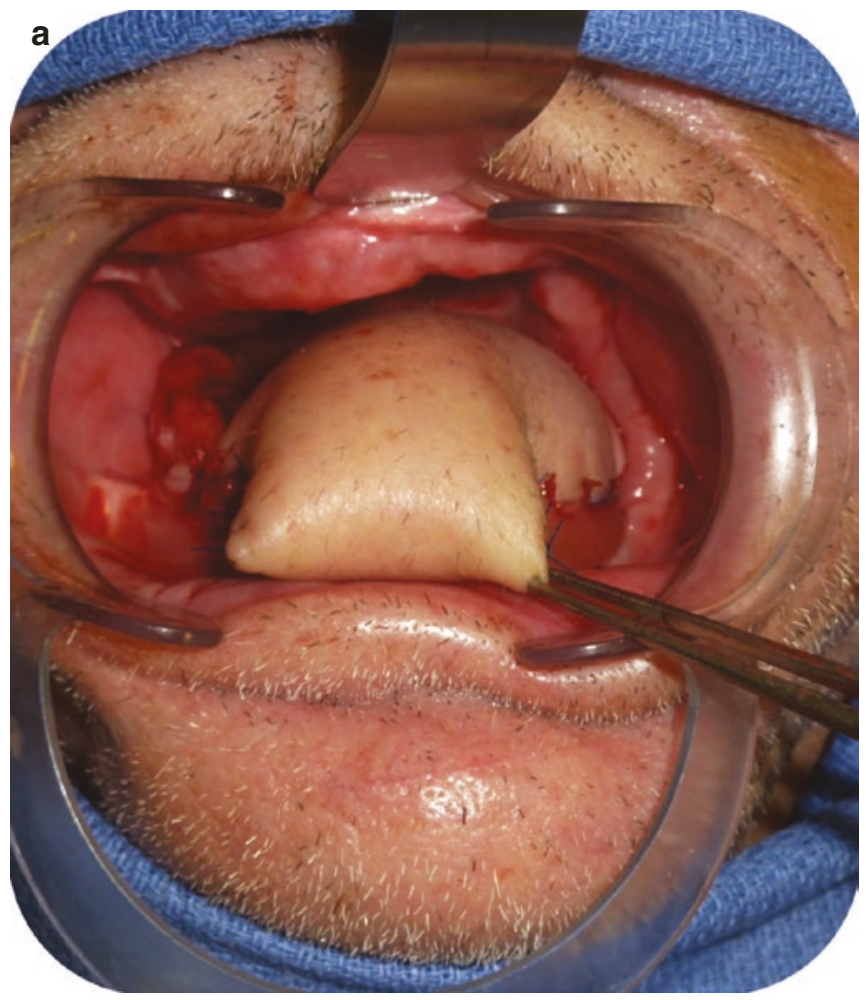

CAssociation of Oral and Maxillofacial Surgeons of India

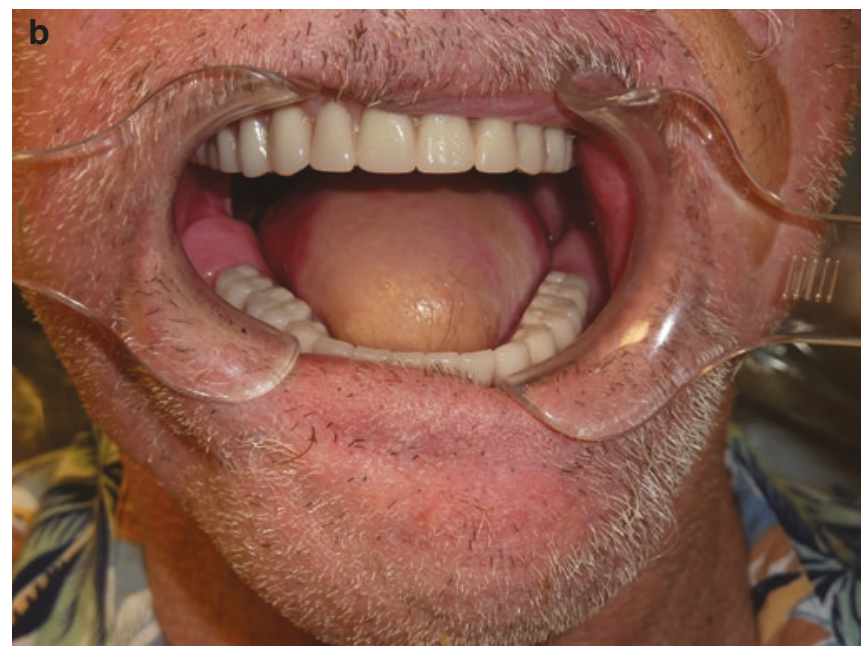

Fig. 86.31 (a) ALT flap inset for glossectomy reconstruction. (b) Late postoperative appearance

\subsection{Facial Reconstruction}

The aims of facial reconstruction differ from those of oral reconstruction. While the emphasis in the latter case is on function, without neglecting cosmesis, the priority here is reversed. Besides the disfigurement itself, patients will often suffer significant and irremediable social detriment due to inadequate facial reconstruction. Cosmetically acceptable results require a detailed understanding of facial anatomy. This is best considered in terms of the facial aesthetic units [44] (Fig. 86.3). This approach was first described by Gonzales-Ulloa [45-48], who demonstrated that scars can be hidden in the natural lines dividing units from one another. Menick later discussed the importance of human perception in reconstruction [49].

\subsubsection{Forehead Reconstruction}

The forehead comprises midline and paired median, lateral, temporal and brow subunits (Fig. 86.32). Small defects can be closed primarily parallel to horizontal RSTLs that run perpendicular to the underlying frontalis muscle fibres. The defect can be extended to an ellipse or with terminal

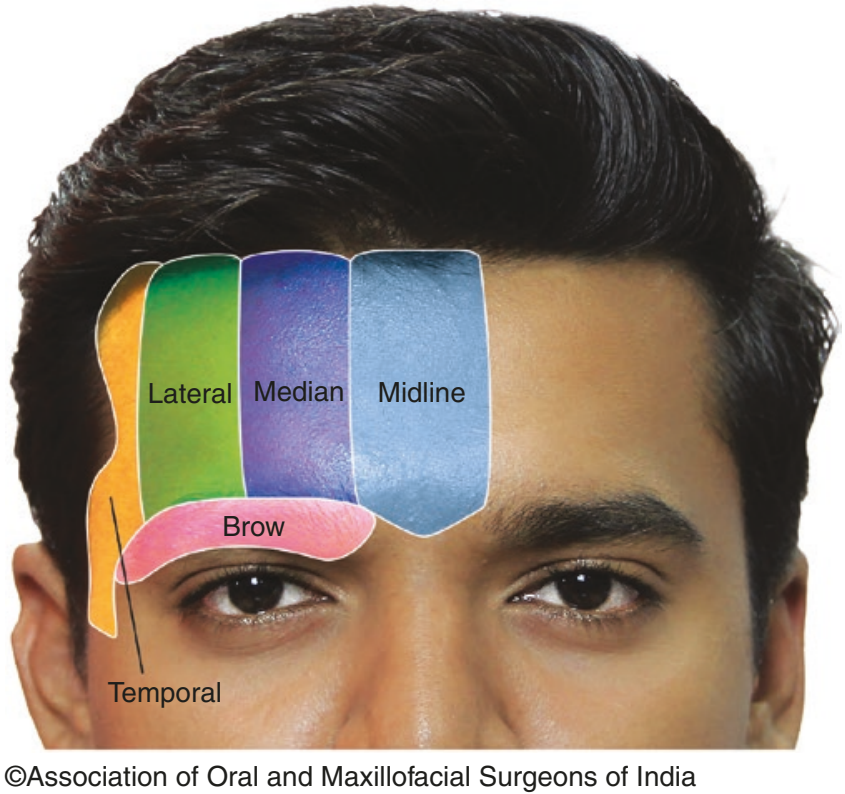

Fig. 86.32 Aesthetic subunits of the forehead

M-plasties to achieve this. Midline defects may be closed vertically with acceptable results, particularly in the aged face. Undermining and careful closure of the galeal layer is important when closing larger defects primarily. 
Split or full-thickness skin grafts can be used for large defects, although there will be a mismatch with the native skin particularly if split thickness. An alternative is tissue expansion either to provide full-thickness skin from a site such as the supraclavicular fossa or locally to provide tissue for a local flap.

Reconstruction of the forehead with local flaps usually has a better cosmetic outcome than skin grafts. Unilateral or bilateral horizontal ' $\mathrm{H}$ ' advancement flaps work well, as does an 'A' to ' $T$ ' flap at the hairline. Finally, large forehead and scalp defects can be reconstructed with free tissue transfer. With this option, often the best cosmetic results are achieved with a radial flap or latissimus dorsi muscle flap combined with a skin graft.

\subsubsection{Eyelid Reconstruction}

The eyelids are of critical importance in protecting the globes and preventing loss of vision through exposure keratitis. The main goals of reconstruction are therefore to recreate a lid that lies passively against the globe without ectropion or entropion and permits full eye closure (Table 86.4). Both the upper and lower eyelids have a bilaminar structure, which has relevance to reconstructive options. The anterior lamella is composed of the thinnest skin in the body and underlying preseptal orbicularis oculi muscle. The posterior lamella is comprised of the tarsal plate and conjunctiva. The tarsal plates impart some rigidity to the eyelids and contain meibomian glands to produce the lipid component of tears. They are around $25 \mathrm{~mm}$ in width and $1 \mathrm{~mm}$ thick, with the upper plate $7-12 \mathrm{~mm}$ and the lower plate $3-4 \mathrm{~mm}$ in height. The upper tarsal plate is attached to the levator palpebrae superioris (oculomotor innervation) muscle via the levator aponeurosis and sympathetically innervated Muller's muscle. The lower plate is attached to orbital septum rather than an aponeurosis.

The orbicularis oculi muscle has three parts. The preseptal and pretarsal components are active in blinking, promoting lachrymal flow from gland to canaliculi and insert into the canthal tendons. The outermost orbital component is involved in voluntary eyelid closure and does not insert into the canthal tendons. There are two preaponeurotic fat pads present in the upper lid and three post septal fat pads in the lower lid (nasal, central and lateral). They are separated by fibrous septa, plus the inferior oblique muscle between nasal and central lower fat pads.

Table 86.4 Aims of eyelid reconstruction

Reconstruction of anterior and posterior lamellae

Adequate supple skin that permits normal eyelid movements

Avoidance of entropion or ectropion

Non-keratinized mucosa adjacent to globe

Degree of rigidity such that lid is applied to the globe in all areas

\subsubsection{Healing by Secondary Intention}

Small superficial defects limited to the anterior lamella may be left to heal by secondary intention particularly in the medial canthal region where the nasal bones resist scar contracture and therefore ectropion. This approach should generally be avoided in central or lateral lower eyelid defects due to the high risk of cicatricial ectropion.

\subsubsection{Primary Closure and Grafts}

Small defects not involving the ciliary margin can be closed parallel to relaxed skin tension lines if lagophthalmos does not result. For larger defects confined to the anterior lamella, full-thickness skin grafts from the opposing lid are ideal, providing a good match with minimal hair and resistance to the contraction associated with split-thickness grafts.

If the defect involves the ciliary margin, primary closure is possible up to one third of the lid width. Typically a 7/0 resorbable vertical mattress suture though meibomian gland orifices is used to align the ciliary margin, the tarsal plate is closed with $6 / 0$ resorbable sutures and finally skin with $6 / 0$ fast resorbing sutures (Fig. 86.33). Conversion to a pentagonal defect with squaring of the tarsal defect and a slight temporal slant to the anterior lamella portion can be helpful to prevent notching of the ciliary margin. A lateral canthotomy and superior or inferior cantholysis can help recruit lateral tissue. Care must be taken to appose both the tarsus and skin to avoid notching of the ciliary margin.

\subsubsection{Local Flaps}

Full-thickness defects up to $60 \%$ of the lower lid width can be repaired with a Tenzel flap [50] (Fig. 86.34), which rotates and advances tissue from the lateral canthus. Alternatively defects of this size can be repaired with a tarsoconjunctival graft and musculocutaneous advancement flap or a Hughes flap [51] (Fig. 86.35). The latter method is a two-stage procedure that involves a pedicled tarsoconjunctival flap from the upper lid covered with skin grafted from one of the upper lids. The pedicle is divided after $4-6$ weeks. To prevent entropion of the upper lid, 3-4 $\mathrm{mm}$ of tarsus should be preserved. This method in reverse has also been described to repair defects of the upper eyelid [52]. A cervicofacial (Mustarde) flap can also be combined with a Hughes flap, free tarsoconjunctival or palatal mucosa or nasal septal graft to reconstruct lower lid defects.

Defects one third to one half the upper lid width can be repaired with a reverse Tenzel flap or sliding tarsoconjunctival flap (Fig. 86.36) and skin graft. Larger defects can be repaired with a Cutler-Beard flap [53] that transfers an infratarsal fullthickness lower lid flap underneath a bridge of preserved lower ciliary margin (Fig. 86.37). The pedicle is divided after 6-8 weeks. Interposition of a cartilage or dermal matrix graft between the lamellae of the flap can improve the form of the reconstructed upper lid [54] (Table 86.5). 
Fig. 86.33 (a-d) Primary closure for small defects involving the ciliary margin. A vertical mattress resorbable suture is placed through the meiobian duct orifice region (a), to oppose the ciliary margin (b). The muscle (c) and skin (d) are then closed in layers

Fig. 86.34 (a-c) Tenzel flap to advance lateral tissue into lower lid defect. A superiorly curved incision is extended laterally through the lateral canthus (a) to allow advancement of a partial thickness flap and remaining lateral lid to close a lower lid defect (b). Excess skin inferior to the defect is excised in the manner of a Burow's triangle

\section{Lid margin repair}
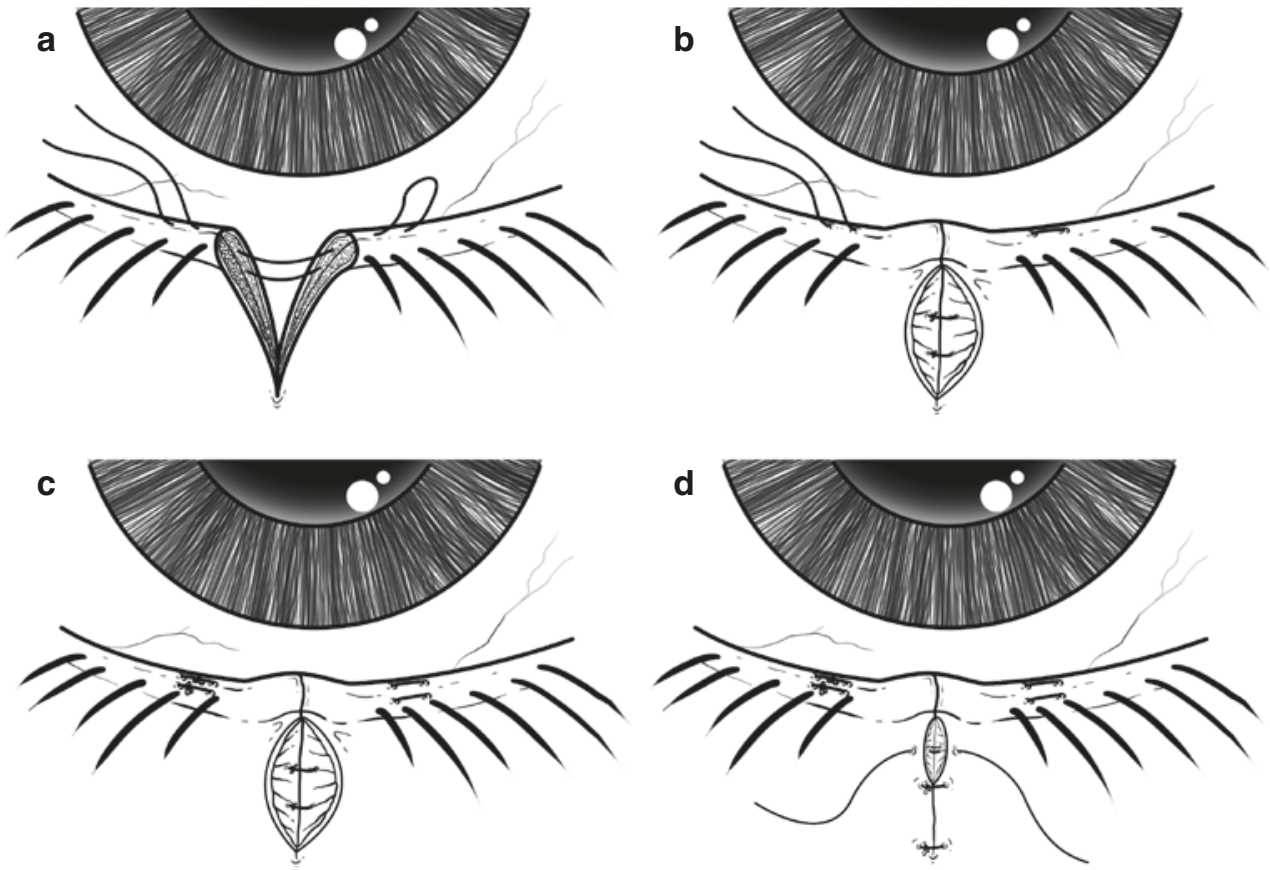

CAssociation of Oral and Maxillofacial Surgeons of India
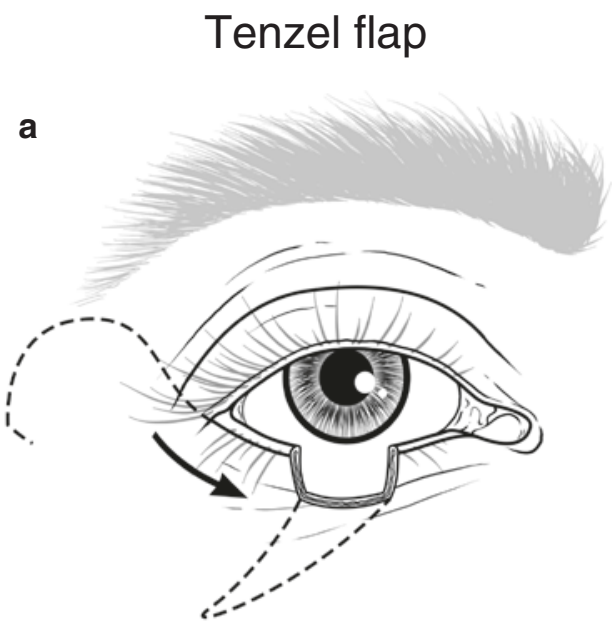

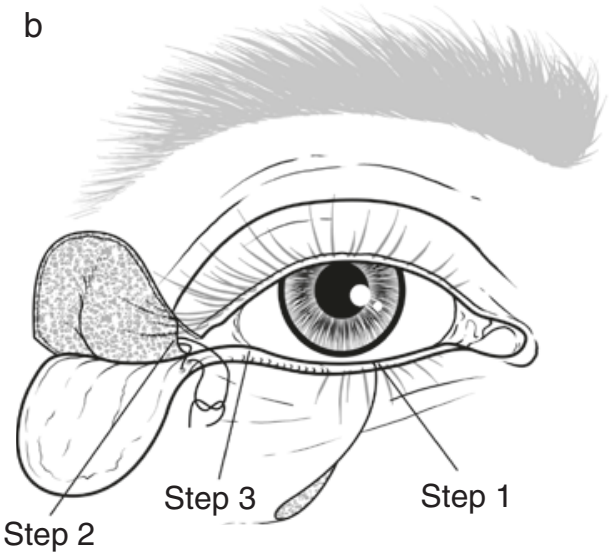

(CAssociation of Oral and Maxillofacial Surgeons of India

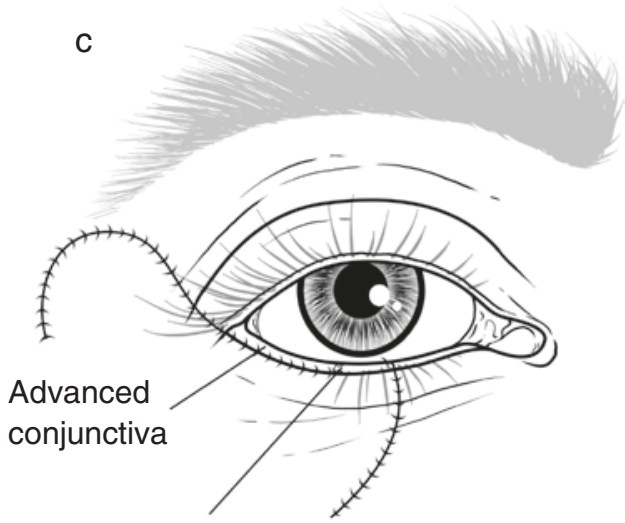

Previous lat. canthus 
Fig. 86.35 (a-d) Hughes tarsoconjunctival flap from upper lid to reconstruct lower lid defect. A lower lid defect

(a) is reconstructed with a superiorly based tarsoconjuctival flap raised from the deep aspect of the upper lid (b-d). The flap is covered with a skin graft from one of the upper lids and the pedicle divided after 4-6 weeks
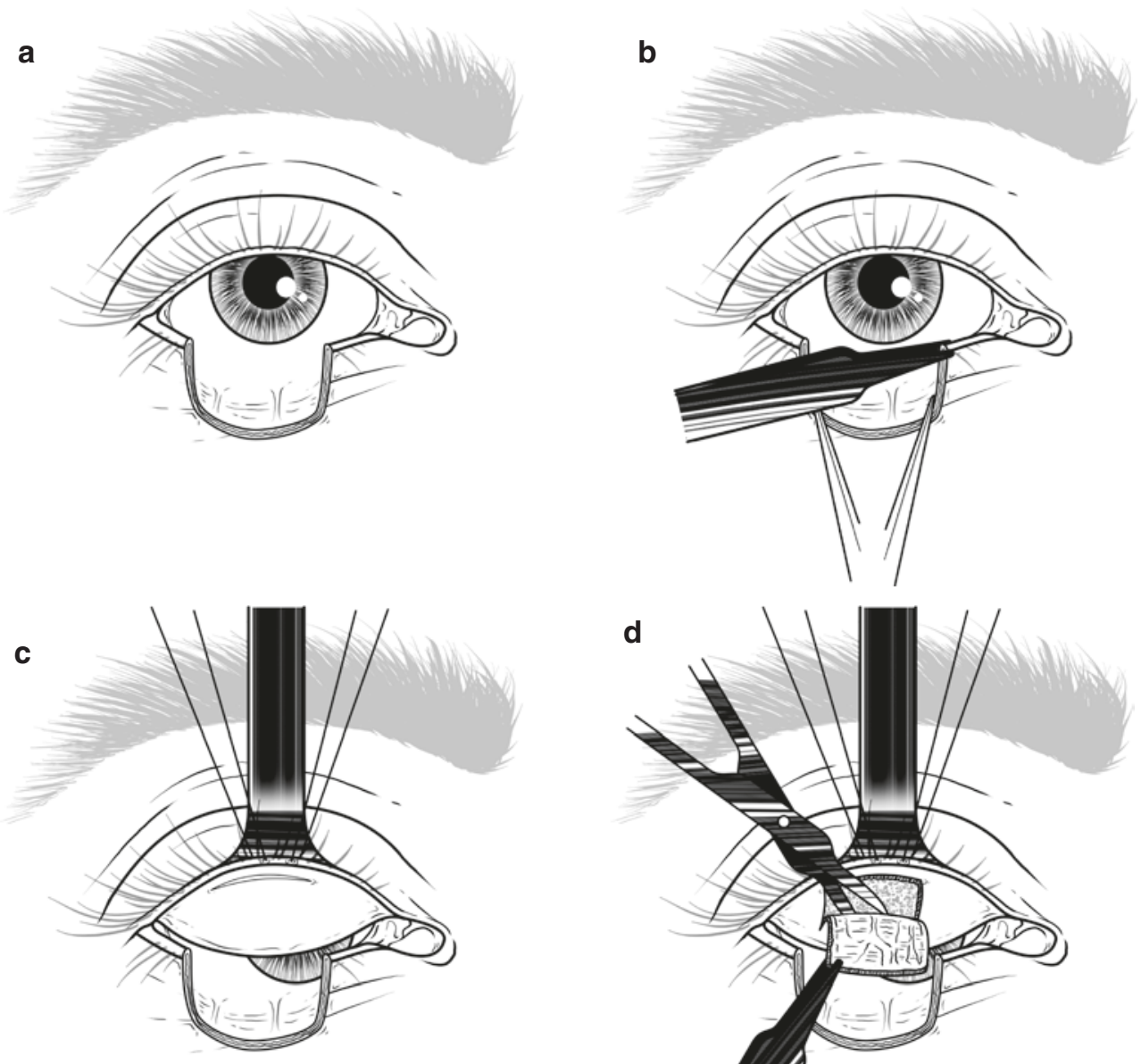

CAssociation of Oral and Maxillofacial Surgeons of India

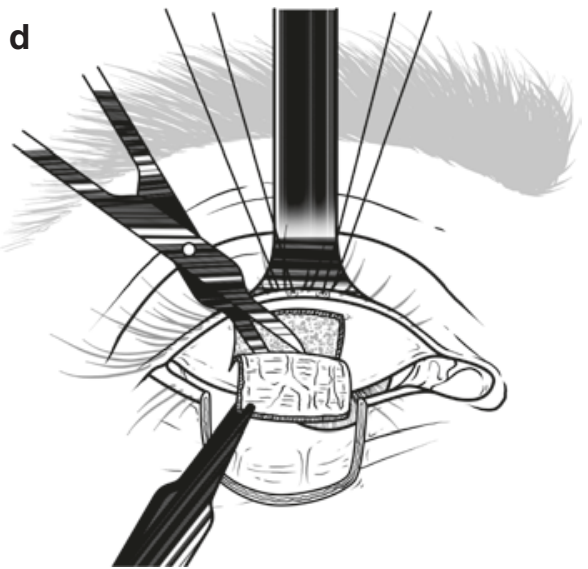

\subsubsection{Ear Reconstruction (Also refer Chap. 35)}

The external ear is a relatively isolated aesthetic unit with its own complex subunit anatomy (Fig. 86.38). Reconstruction requires attention to shape, angular orientation with respect to the adjacent skull, and symmetry with the contralateral ear [55]. Of these three points, the last is the most important. Finally, the reconstructed ear should serve as support for spectacles or hearing aids (Table 86.6).

The major constitutive subunits, working from peripheral to central, are the helix, scapha, antihelix and concha (subdivided into cymba and cavum). The tragus, antitragus and lobule are less critical to overall auricular aesthetics, as a defect involving these subunits has minimal effect on the shape of the remainder of the external ear.

Orientation with respect to the skull follows these general guidelines [55]:

1. Auricular height $=$ distance between lateral orbital rim and root of helix at the level of the brow.
2. Approximately $15^{\circ}$ deviation from the skull in the vertical axis.

3. Approximately $25-30^{\circ}$ deviation from the skull in the horizontal axis.

4. Highest point of helix level with lateral brow.

5. Helical rim protrudes $1-2.5 \mathrm{~cm}$ from skull.

The following will concentrate on helical defects, since the helix is the most common site, and many lesions centred in other regions will extend to involve it as well [56]. The classical reconstructive ladder is somewhat modified for defects of the ear. For defects overlying intact perichondrium, a full-thickness skin graft is the optimal technique, rather than primary closure [55]. Alternative approaches must be used when perichondrium has been resected, as denuded cartilage will not support a skin graft. If the defect exposes cartilage in an area where it can be resected without altering the shape of the ear, it should be resected down to the opposing perichondrium, which should be covered with a skin graft [55]. The retroauricular skin is the best colour match, and the scar at the donor site is well hidden by the ear. 

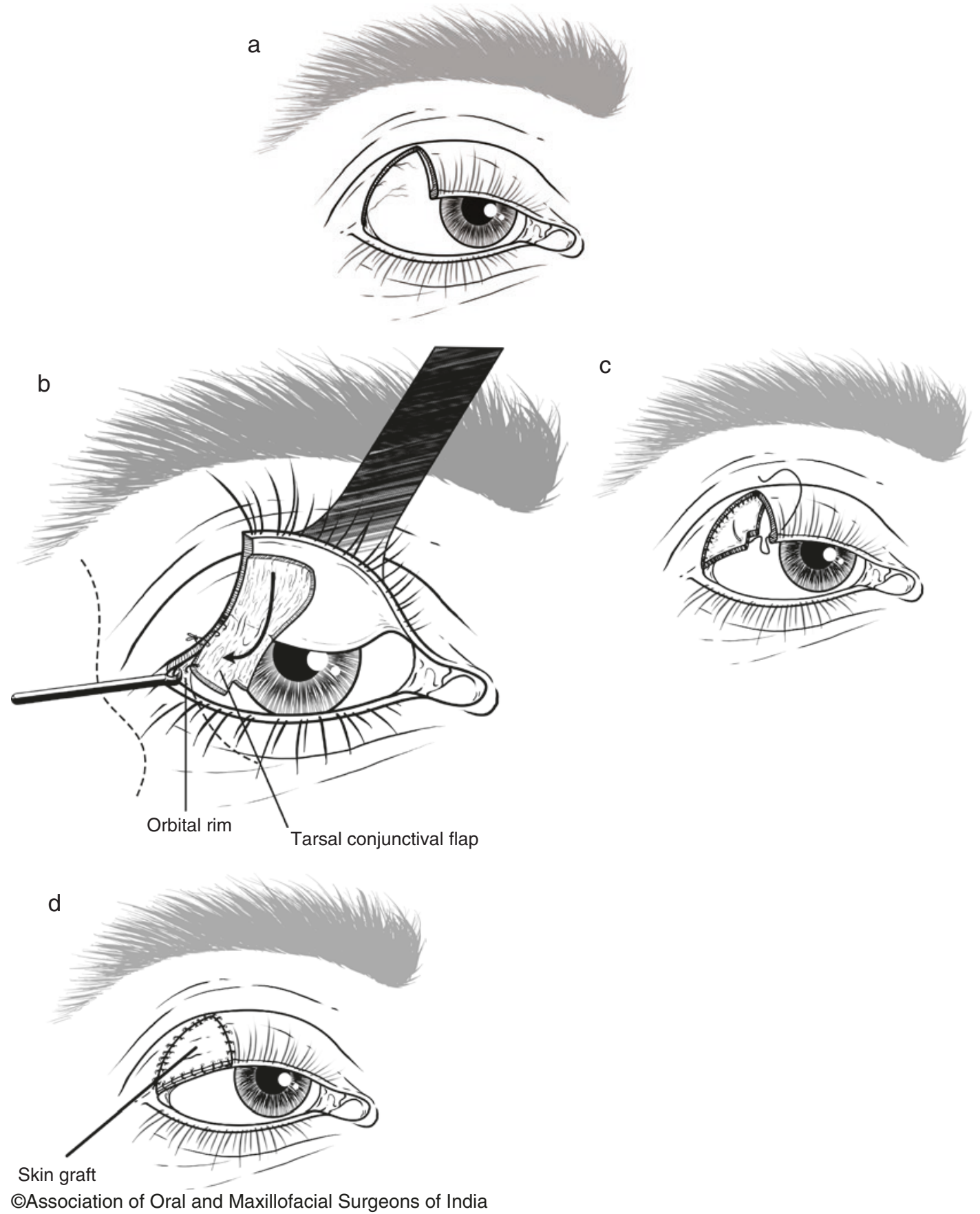

Fig. 86.36 (a-d) Sliding tarsoconjunctival flap for upper lid defect repair. An upper lid defect (a) is repaired with a superiorly based tarsoconjunctival flap raised from the adjacent remaining lid (b). The flap is

Resection of shape-determining cartilage requires further subdivision. Small helical defects, ideally less than $1.5 \mathrm{~cm}$, can be closed primarily [57]. Primary closure can be facilitated by the extension of the defect into a wedge excision.

For larger defects, the resulting distortion exaggerates the ear's lateral depth and makes it stand out too far from the skull. Defects between 1.5 and $2.5 \mathrm{~cm}$, or roughly one third of the ear's height, can be closed by means of the helical advance- transposed and inset into the defect (c), prior to coverage with a skin graft harvested from another eyelid (d)

ment flap first described by Antia and Buch [57-59] (Fig. 86.39). In this repair, the helical sulcus is incised superiorly and inferiorly through the cartilage, but sparing the posterior perichondrium and skin, which then serves as the vascular supply for the flap. A crescent of skin and cartilage can be resected from the scapha anterior to this incision, in order to decrease the size discrepancy between the helix and antihelix and thereby the degree of cupping in the final repair [57]. 
Fig. 86.37 (a-d) Cutler-

Beard full-thickness lower lid flap to upper lid defect
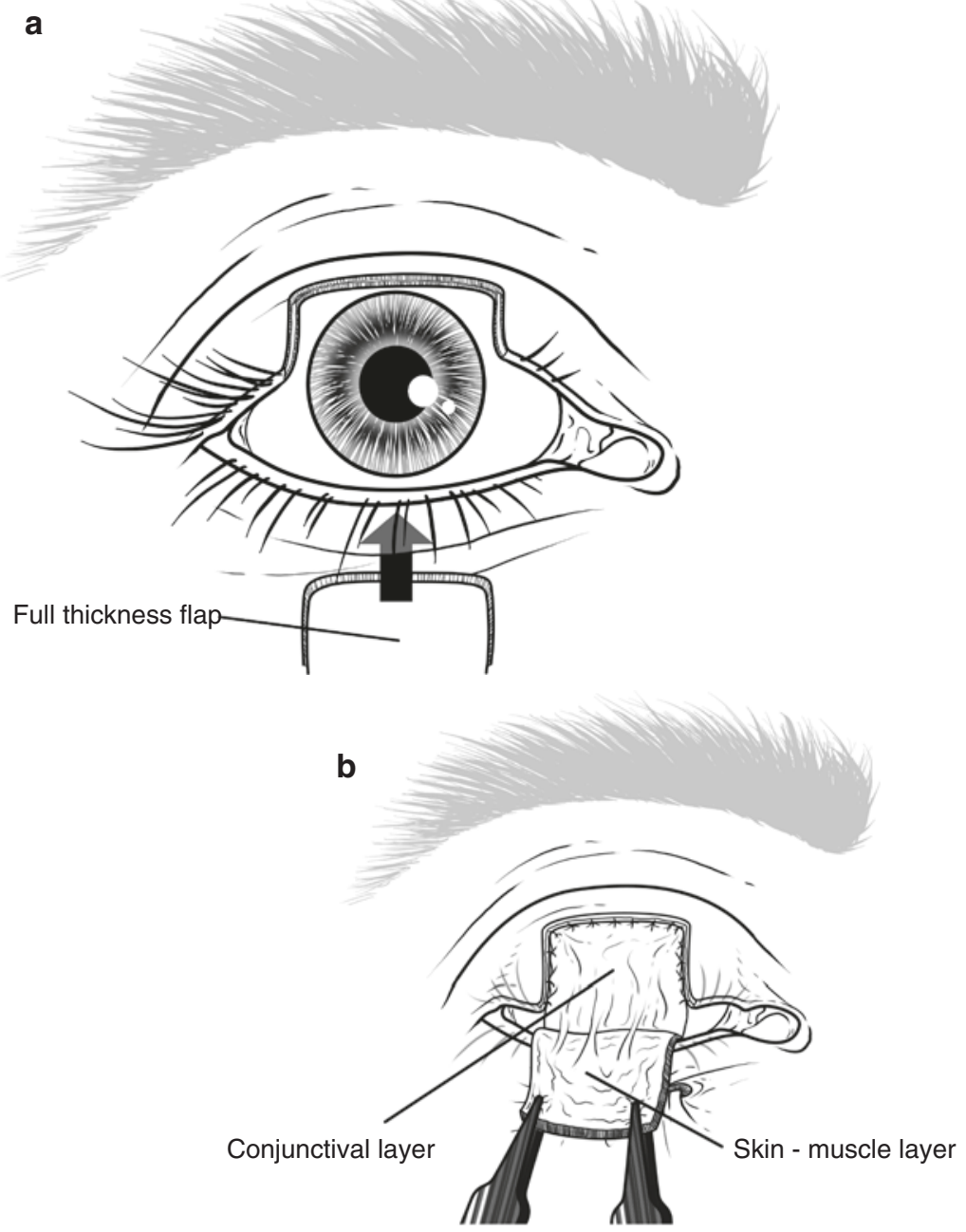

C

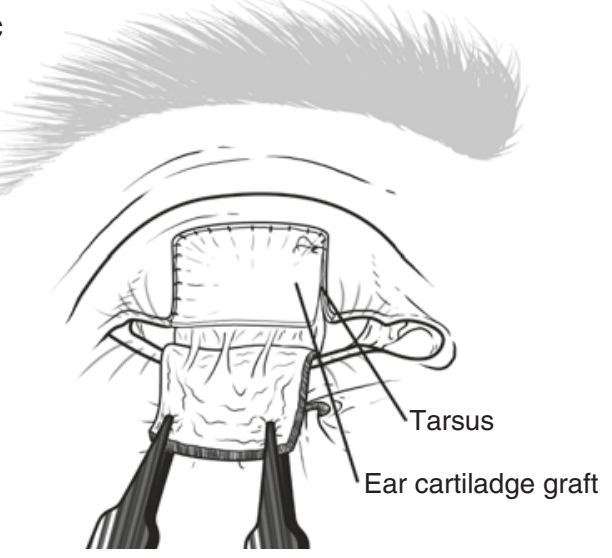

(CAssociation of Oral and Maxillofacial Surgeons of India d

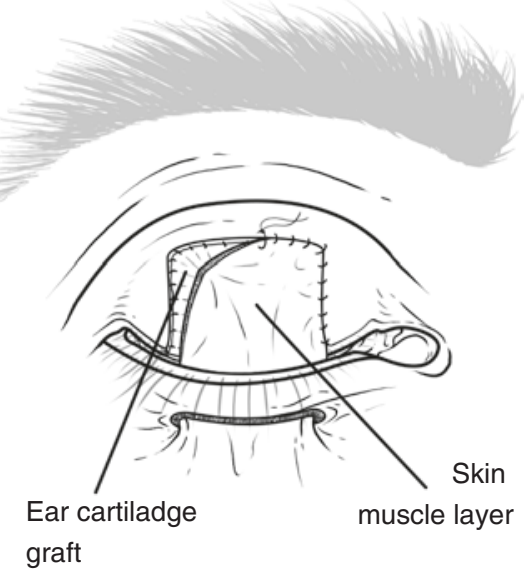


Table 86.5 Options for eyelid reconstruction

\section{Lower eyelid reconstruction}

Direct closure ( $<30-45 \%$ defects)

Lateral canthotomy and inferior cantholysis (gains $5 \mathrm{~mm}$ )

Tenzel flap ( $<60 \%$ defects)

Tarsoconjunctival graft and musculocutaneous advancement

Hughes flap

Mustarde flap + graft for posterior lamella

Upper eyelid reconstruction

Direct closure

Lateral canthotomy and superior cantholysis

Sliding tarsoconjunctival flap

Cutler-Beard flap (60\%-100\% defects)

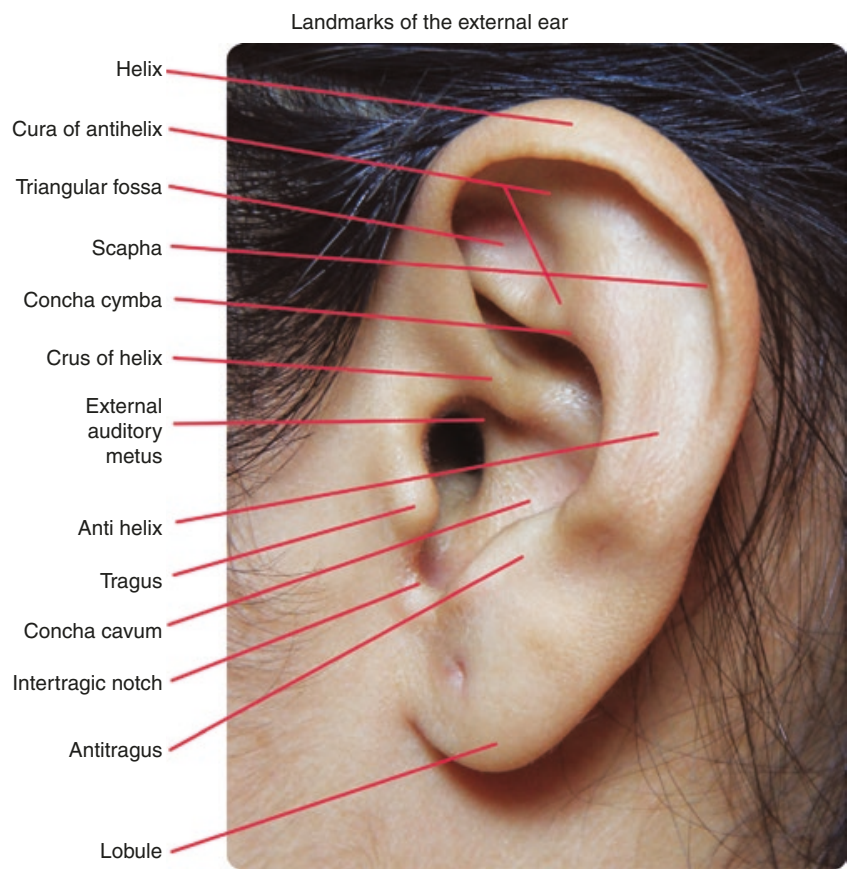

CAssociation of Oral and Maxillofacial Surgeons of India

Fig. 86.38 Anatomy of the pinna

Table 86.6 Aims of ear reconstruction

Recreation of natural morphology

Symmetry with contralateral ear

Height

Projection

Size

Support for spectacles/hearing aids

Some authors suggest that the Antia-Buch approach is not appropriate for larger marginal defects, since it induces excessive microtia [55]. Others advocate a more aggressive Antia-Buch repair [57], arguing that the microtia will only be noticeable in those exceptional viewing situations when both ears are visible at once. Alternate strategies for a larger defect include adjacent tissue transfer such as a staged tubular pedicled graft [60] or retroauricular flap [61].
For near or complete loss of the external ear, the three options are:

1. No reconstruction.

2. Staged autogenous reconstruction.

3. Prosthetic reconstruction.

A patient wishing to avoid repeated surgery, or a poor surgical candidate, might be best served by the first option. Staged autogenous reconstruction was pioneered by Tanzer [62], who described a six-stage approach. This has since been simplified to a three or two-stage approach by the work of Brent [63] and then Nagata [64]. In summary, a cartilaginous framework is fashioned from costal cartilage, sutured to the remainder of the native ear and reposed beneath the skin as stage one. Stage two refashions the posterior aspect of the ear and establishes the correct angulation away from the skull. Exogenous cartilage substitutes can be used for this approach as well.

Finally, the entire external ear can be reconstructed with a prosthesis attached via adhesive or osseointegrated implants [65-67]. This solution is often best for patients in who the surrounding skin is compromised, for example by radiation or burns [55]. Typically implants require a minimum of $4 \mathrm{~mm}$ thickness of temporal bone and connect to the prosthesis via magnets.

\subsubsection{Nasal Reconstruction}

Nasal reconstruction must be considered with respect to aesthetic subunits (Fig. 86.40). The nine nasal subunits are the dorsum, lateral walls, tip, ala, soft triangles and columella. A detailed discussion of nasal aesthetics is beyond the scope of this text, but we will describe the approaches most pertinent to trauma and oncologic reconstruction. Only the smallest nasal defects can be closed primarily. However, the available regional flap options are versatile and highly cosmetically acceptable. Lateral defects can often be closed with a nasolabial flap, providing a good colour match and hiding the donor scar in the nasolabial fold [68]. Some blunting of the nasofacial angle can occur particularly if not resisted with deep sutures. Larger defects $(>2 \mathrm{~cm}$.) cannot be closed with the limited volume of tissue available, and the dorsum and tip are not accessible with this flap [69]. Other options are the bilobed rotation flap for sidewall defects or sliding Rintala flap for dorsal and tip defects.

Larger defects, and those centred near the midline, are generally best repaired with a paramedian forehead flap. This approach was first described by Sushruta in the sixthcentury BC [70] and has undergone very little change since. 
Fig.86.39 (a-d) Antia-Buch helical rim advancement flap. A defect of the helix is repaired by advancement of adjacent helix. Full thickness incisions are made along the inside of the helix $+/-$ a partial thickness incision anterior to the root of the helix (dotted lines, (a). A crescent or wedge of scaphal cartilage is excised (b) to reduce its circumference and permit approximation of the remaining helix (c). Finally, excess skin overlying the scaphal cartilage can be trimmed and the incisions closed (d)
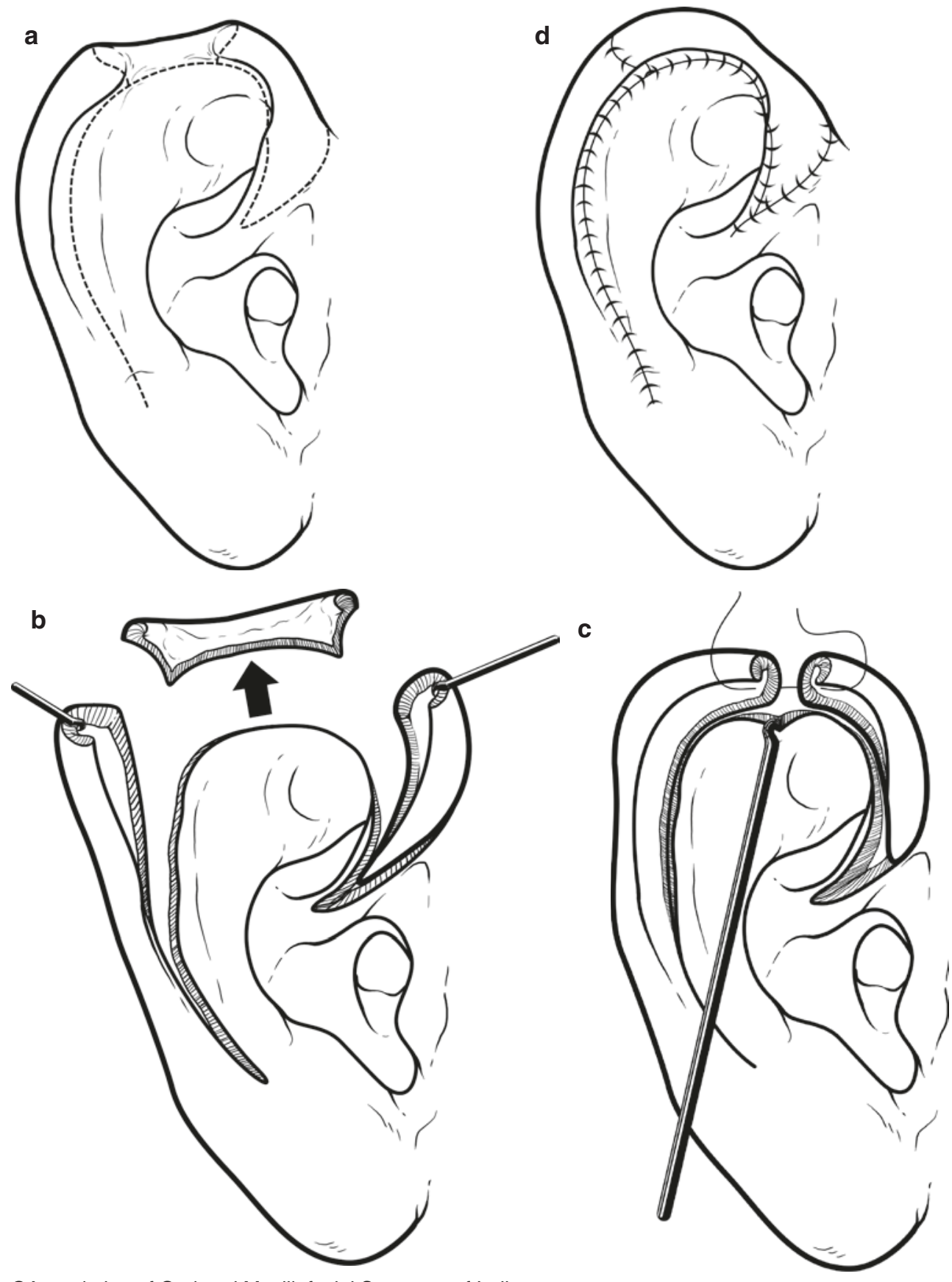

CAssociation of Oral and Maxillofacial Surgeons of India
The flap provides skin of similar character and sufficient size to replace an entire nasal subunit and also a portion of nasal vestibule for alar defects, potentially improving aesthetic outcome $[68,69]$. The first stage involves rotation of a paramedian skin paddle about a narrow pedicle based on the supratrochlear vessels. The flap is generally based on the contralateral vessels, as this produces less torsion of the vessels. The dissection is carried out in the subcutaneous plane at the distal aspect, to provide pliable skin for the repair, but transfers to the subgaleal and ultimately subperiosteal planes as it proceeds proximally towards the pedicle. The paddle is sutured in place, with stents for the nares if necessary. The second stage is carried out approximately 3 weeks after the first, in order to provide for neovascularization. At this stage, the pedicle is divided and the superior edge of the flap inset. A third stage can be carried out to debulk the flap and is often required for ideal aesthetic outcome [69]. In patients with vascular disease, a greater proportion of the flap can be carried out in the subgaleal plane, and a debulking stage performed before division and inset, in order to decrease the chance of flap necrosis [70]. Reconstruction of alar nasal mucosa in full-thickness defects can be achieved with a 


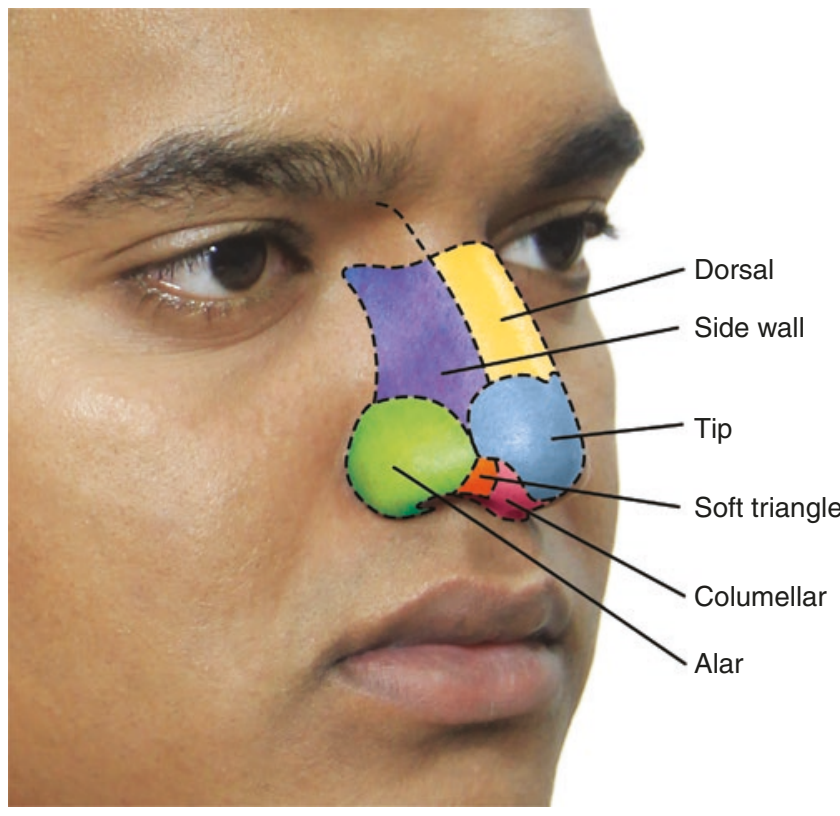

Subunits of contour

(CAssociation of Oral and Maxillofacial Surgeons of India

Fig. 86.40 Aesthetic subunits of the nose

hinged nasal septum mucoperichondrial flap. Alar rim defects can also benefit from reconstruction with composite grafts harvested from the lobule or helical rim of the pinna.

Defects involving significant bony or cartilaginous destruction require repair with similar tissue. Small cartilaginous defects can be reconstructed with nasal septal cartilage [68], but only a limited volume can be harvested without impairing septal integrity and tip support. Grafts may also be taken from the ear or rib; the first confers less morbidity and has a favourable contour for alar reconstruction, while the second provides a larger volume of cartilage stock [55]. Many potential donor sites are available for bony defects, including calvarium, mandible, iliac crest and long bones (tibia or radius). The dorsal contour is the most important to reconstruct; this can be accomplished with an osseous strut graft [69].

In total or subtotal nasal defects, reconstruction of the internal and external soft tissue and hard tissue requires consideration. Most commonly a radial forearm free flap is employed and can be harvested with a portion of radial bone for use as a dorsal strut [71]. The best cosmetic outcome is generally achieved with this flap when combined with paramedian forehead flap to reconstruct the external skin. Finally, nasal prostheses require less surgery and can provide an excellent match in appearance to the premorbid nose. They can be retained with adhesive, spectacles or osseointegrated implants. Their chief disadvantage is cost, as they must be replaced every 1 to 2 years [68].

\subsubsection{Reconstruction of the Extraoral Cheek}

The greater laxity and simpler architecture of the skin of the cheek allows primary closure of most defects, usually by conversion to an ellipse. However, even moderate tension can result in a wide scar or distort adjacent aesthetic units, and ectropion of the lower eyelid is a particular concern here. If primary closure can be achieved to lie along the nasolabial or preauricular creases, this can give an excellent cosmetic outcome. For larger defects, these natural lines can be utilized with cervicofacial rotation flap reconstruction.

\section{References}

1. Ray E. Head and neck reconstructive surgery. In: Cancer treatment and research. New York, NY: Springer; 2018. p. 123-43.

2. Erba P, Ogawa R, Vyas R, Orgill DP. The reconstructive matrix: a new paradigm in reconstructive plastic surgery. Plast Reconstr Surg. 2010 Aug;126(2):492-8.

3. El-Marakby HH. The reliability of pectoralis major myocutaneous flap in head and neck reconstruction. J Egypt Natl Canc Inst. 2006 Mar;18(1):41-50.

4. Shah JP, Haribhakti V, Loree TR, Sutaria P. Complications of the pectoralis major myocutaneous flap in head and neck reconstruction. Am J Surg. 1990 Oct;160(4):352-5.

5. Zitelli JA. Wound healing by secondary intention. A cosmetic appraisal. J Am Acad Dermatol. 1983 Sep;9(3):407-15.

6. Leonard AL, Hanke CW. Second intention healing for intermediate and large postsurgical defects of the lip. J Am Acad Dermatol. 2007 Nov;57(5):832-5.

7. Jin X, Teng L, Zhang C, Xu J, Lu J, Zhang B, et al. Reconstruction of partial-thickness vermilion defects with a mucosal $\mathrm{V}-\mathrm{Y}$ advancement flap based on the orbicularis oris muscle. J Plast Reconstr Aesthetic Surg. 2011 Apr;64(4):472-6.

8. Wagner DJD, Newman DMH. Bipedicled axial cross-lip flap for correction of major vermilion deficiency after cleft lip repair. Los Angeles, CA: Sage; 2017.

9. Ceran C, Demirseren ME, Sarici M, Durgun M, Tekin F. Tongue flap as a reconstructive option in intraoral defects. J Craniofac Surg. 2013 May;24(3):972-4.

10. Levi B, Ricci JA, Donelan MB. Vermillion reconstruction with anal verge transitional epithelium. J Burn Care Res. 2017 May 20;39(2):1.

11. Sood A, Paik A, Lee E. Lower lip reconstruction: karapandzic flap. Eplasty. 2013;13:ic17.

12. Karapandzic M. Reconstruction of lip defects by local arterial flaps. Br J Plast Surg. 1974 Jan;27(1):93-7.

13. Bernard C. Cancer de la levre inferieure opere par un procede nouveau. Bull Mem Soc Chir Paris. 1853;3:357-64.

14. Webster RC, Coffey RJ, Kelleher RE. Total and partial reconstruction of the lower lip with innervated muscle-bearing flaps. Plast Reconstr Surg. 1960 Apr;25(3):360-71.

15. Pirgousis P, Fernandes R. Reconstruction of subtotal defects of the lower lip: a review of current techniques and a proposed modification. J Oral Maxillofac Surg. 2011 Jan;69(1):295-9.

16. Fujimori R. Gate flap for the total reconstruction of the lower lip. $\mathrm{Br}$ J Plast Surg. 1980 Jul;33(3):340-5.

17. Aytekin A, Ay A, Aytekin O. Total upper lip reconstruction with bilateral Fujimori gate flaps. Plast Reconstr Surg. 2003 Feb;111(2):797-800. 
18. Agostini T. The Sabattini-Abbé flap: a historical note. Plast Reconstr Surg. 2009 Feb;123(2):767.

19. Abbe R. A new plastic operation for the relief of deformity due to double harelip. Plast Reconstr Surg. 1968 Nov;42(5):481-3.

20. Webster JP. Crescentic peri-alar cheek excision for upper lip flap advancement with a short history of upper lip repair. Plast Reconstr Surg. 1955;16(6):434-64.

21. Fernandes R, Clemow J. Outcomes of total or near-total lip reconstruction with microvascular tissue transfer. J Oral Maxillofac Surg. 2012 Dec;70(12):2899-906.

22. Sakai S, Soeda S, Endo T, Ishii M, Uchiumi E. A compound radial artery forearm flap for the reconstruction of lip and chin defect. $\mathrm{Br}$ J Plast Surg. 1989;42(3):337-8.

23. Cordova A, D'Arpa S, Moschella F. Gracilis free muscle transfer for morpho-functional reconstruction of the lower lip. Head Neck. 2008 May;30(5):684-9.

24. Sacak B, Gurunluoglu R. The innervated gracilis muscle for microsurgical functional lip reconstruction: review of the literature. Ann Plast Surg. 2015 Feb;74(2):204-9.

25. Gurunluoglu R, Glasgow M, Williams SA, Gurunluoglu A, Antrobus J, Eusterman V. Functional reconstruction of total lower lip defects using innervated gracilis flap in the setting of highenergy ballistic injury to the lower face: preliminary report. J Plast Reconstr Aesthetic Surg. Churchill Livingstone. 2012 Oct $1 ; 65(10): 1335-42$.

26. Lyons GB, Milroy BC, Lendvay PG, Teston LM. Upper lip reconstruction: use of the free superficial temporal artery hair-bearing flap. Br J Plast Surg. 1989 May;42(3):333-6.

27. Chang K-P, Lai C-S, Tsai C-C, Lin T-M, Lin S-D. Total upper lip reconstruction with a free temporal scalp flap: long-term follow-up. Head Neck. 2003 Jul;25(7):602-5.

28. Dean A, Alamillos F, García-López A, Sánchez J, Peñalba M. The buccal fat pad flap in oral reconstruction. Head Neck. 2001 May;23(5):383-8.

29. Liu F, Wang L, Pang S, Kan Q. Reconstruction of full-thickness buccal defects with folded radial forearm flaps: a retrospective clinical study. Medicine (Baltimore). 2017 Aug;96(32):e7344.

30. Liu Z-M, Wu D, Liu X-K, Liu W-W, Li H, Li Q, et al. Reconstruction of through-and-through cheek defects with folded free anterolateral thigh flaps. J Oral Maxillofac Surg. 2013 May;71(5):960-4.

31. Liu YM, Sherris DA. Static procedures for the management of the midface and lower face. Facial Plast Surg. 2008 May;24(2):211-5.

32. Coyle M, Godden A, Brennan PA, Cascarini L, Coombes D, Kerawala C, et al. Dynamic reanimation for facial palsy: an overview. Br J Oral Maxillofac Surg. 2013 Dec;51(8):679-83.

33. Martin D, Pascal JF, Baudet J, Mondie JM, Farhat JB, Athoum A, et al. The submental island flap: a new donor site. Anatomy and clinical applications as a free or pedicled flap. Plast Reconstr Surg. 1993 Oct;92(5):867-73.

34. Cariati P, Cabello Serrano A, Marin Fernandez AB, Perez de Perceval Tara M, Juliá MA, Ildefonso Martinez Lara M. Is submental flap safe for the oncological reconstruction of the oral cavity? J Stomatol oral Maxillofac Surg. 2018 Jun 27;119(4):284-7.

35. Howard BE, Nagel TH, Donald CB, Hinni ML, Hayden RE. Oncologic safety of the submental flap for reconstruction in oral cavity malignancies. Otolaryngol Head Neck Surg. 2014 Apr;150(4):558-62.

36. Wu Y, Tang P, Qi Y, Xu Z, He Y. Evaluation for submental island flap. Zhonghua Kou Qiang Yi Xue Za Zhi. 2002 Nov;37(6):418-20.

37. Taghinia AH, Movassaghi K, Wang AX, Pribaz JJ. Reconstruction of the upper aerodigestive tract with the submental artery flap. Plast Reconstr Surg. 2009 Feb;123(2):562-70.

38. Deganello A, Manciocco V, Dolivet G, Leemans CR, Spriano G. Infrahyoid fascio-myocutaneous flap as an alternative to free radial forearm flap in head and neck reconstruction. Head Neck. 2007 Mar;29(3):285-91.
39. Mosier K, Liu W-C, Behin B, Lee C, Baredes S. Cortical adaptation following partial Glossectomy with primary closure: implications for reconstruction of the Oral tongue. Ann Otol Rhinol Laryngol. 2005 Sep 28;114(9):681-7.

40. Brown L, Rieger JM, Harris J, Seikaly H. A longitudinal study of functional outcomes after surgical resection and microvascular reconstruction for Oral Cancer: tongue mobility and swallowing function. J Oral Maxillofac Surg. 2010 Nov;68(11):2690-700.

41. Biglioli F, Liviero F, Frigerio A, Rezzonico A, Brusati R. Function of the sensate free forearm flap after partial glossectomy. J CranioMaxillofacial Surg. 2006 Sep;34(6):332-9.

42. Kimata Y, Sakuraba M, Hishinuma S, Ebihara S, Hayashi R, Asakage T, et al. Analysis of the relations between the shape of the reconstructed tongue and postoperative functions after subtotal or total glossectomy. Laryngoscope. 2003;113(5):905-9.

43. Weber RS, Ohlms L, Bowman J, Jacob R, Goepfert H. Functional results after Total or near Total Glossectomy with laryngeal preservation. Arch Otolaryngol Neck Surg. 1991;117(5):512-5.

44. Fattahi TT. An overview of facial aesthetic units. J Oral Maxillofac Surg. 2003 Oct;61(10):1207-11.

45. González-Ulloa M. Restoration of the face covering by means of selected skin in regional tsthetic units. Br J Plast Surg Elsevier. 1956 Jan;9:212-21.

46. González-Ulloa M. Regional aesthetic units of the face. Plast Reconstr Surg. 1987 Mar;79(3):489-90.

47. Gonzalez-Ulloa M, Stevens E. Reconstruction of the nose and forehead by means of regional aesthetic units. Br J Plast Surg. 1961 Jan; 13:305-9.

48. Gonzalez-Ulloa M, Castillo A, Stevens E, Alvarez Fuertes G, Leonelli F, Ubaldo F. Preliminary study of the total restoration of the facial skin. Plast Reconstr Surg (1946). 1954 Mar;13(3):151-61.

49. Thompson S, Menick FJ. Aesthetic facial reconstruction: blending human perception and the facial subunit theory. Plast Surg Nurs. 1994;14(4):211-6. 224

50. Tenzel RR. Surgical techniques and problems in cosmetic blepharoplasty. Trans Am Acad Ophthalmol Otolaryngol. 1969;73(6):1154-61.

51. McClellan WT, Rawson AE, Wendell L. Hughes' life and contributions to plastic surgery. Plast Reconstr Surg. 2011 Dec;128(6):765e-72e.

52. Mauriello JA, Antonacci R. Single tarsoconjunctival flap (lower eyelid) for upper eyelid reconstruction,(reverse modified Hughes procedure). Ophthalmic Surg. 1994 Jun;25(6):374-8.

53. Cutler NL, Beard C. A method for partial and total upper lid reconstruction. Am J Ophthalmol. 1955 Jan;39(1):1-7.

54. Mandal SK, Fleming JC, Reddy SG, Fowler BT. Total upper eyelid reconstruction with modified cutler-beard procedure using autogenous auricular cartilage. J Clin Diagn Res. 2016 Aug; 10(8):NC01-4.

55. Louis PJ, Aponte-Wesson RA, Fernandes RP, Clemow J. Autogenous and prosthetic reconstruction of the ear. Oral Maxillofac Surg Clin North Am. 2013 May;25(2):271-86.

56. Thomas SS, Matthews RN. Squamous cell carcinoma of the pinna: a 6-year study. Br J Plast Surg. 1994 Mar;47(2):81-5.

57. Tay S, Nikkhah D, Teo TC. The antia-buch flap revisited. Clin Otolaryngol. 2017 Aug;42(4):951-3.

58. Antia NH, Buch VI. Chondrocutaneous advancement flap for the marginal defect of the ear. Plast Reconstr Surg. 1967 May;39(5):472-7.

59. Krunic AL, Weitzul S, Taylor RS. Chondrocutaneous advancement flap for reconstruction of helical rim defects in dermatologic surgery. Australas J Dermatol. 2006 Nov;47(4):296-9.

60. Masud D, Tzafetta K. The "double headed slug flap": a simple technique to reconstruct large helical rim defects. J Plast Reconstr Aesthet Surg. 2012 Oct;65(10):1410-3. 
61. Cordova A, Pirrello R, D’Arpa S, Moschella F. Superior pedicle Retroauricular Island flap for ear and temporal region reconstruction. Ann Plast Surg. 2008 Jun;60(6):652-7.

62. Tanzer RC. Total reconstruction of the auricle. The evolution of a plan of treatment. Plast Reconstr Surg. 1971 Jun;47(6):523-33.

63. Brent B. Ear reconstruction with an expansile framework of autogenous rib cartilage. Plast Reconstr Surg. 1974 Jun;53(6):619-28.

64. Nagata S. A new method of total reconstruction of the auricle for microtia. Plast Reconstr Surg. 1993 Aug;92(2):187-201.

65. Mevio E, Facca L, Mullace M, Sbrocca M, Gorini E, Artesi L, et al. Osseointegrated implants in patients with auricular defects: a case series study. Acta Otorhinolaryngol Ital. 2015 Jun;35(3):186-90.

66. Granström G, Bergström K, Tjellström A. The bone-anchored hearing aid and bone-anchored Epithesis for congenital ear malformations. Otolaryngol Neck Surg. 1993 Jul;109(1):46-53.
67. Gentile P, Bottini DJ, Colicchia GM, Trimarco A, Cervelli V. Burns: bone-anchored, extra-oral implantology. J Burn Care Res. 2008 Jul;29(4):627-31.

68. Fernandes JR, Pribaz JJ, Lim AA, Guo L. Nasal reconstruction. Ann Plast Surg. 2018 Dec;81(6S Suppl 1):S30-4.

69. Menick FJ. Nasal reconstruction. Plast Reconstr Surg. 2010 Apr;125(4):138e-50e.

70. Shokri T, Kadakia S, Saman M, Habal M, Kohlert S, Sokoya M, et al. The Paramedian forehead flap for nasal reconstruction. J Craniofac Surg. 2018 Dec;30(2):330-3.

71. Koshima I, Tsutsui T, Nanba Y, Takahashi Y, Akisada K. Free radial forearm osteocutaneous perforator flap for reconstruction of total nasal defects. J Reconstr Microsurg 2002 Oct;18(7):585-588. discussion 589-90.

Open Access This chapter is licensed under the terms of the Creative Commons Attribution 4.0 International License (http://creativecommons. org/licenses/by/4.0/), which permits use, sharing, adaptation, distribution and reproduction in any medium or format, as long as you give appropriate credit to the original author(s) and the source, provide a link to the Creative Commons license and indicate if changes were made.

The images or other third party material in this chapter are included in the chapter's Creative Commons license, unless indicated otherwise in a credit line to the material. If material is not included in the chapter's Creative Commons license and your intended use is not permitted by statutory regulation or exceeds the permitted use, you will need to obtain permission directly from the copyright holder. 